\title{
HEAVY METAL MIGRATION ALONG A RURAL HIGHWAY ROUTE: ILESHA-AKURE ROADSIDE SOIL, SOUTHWESTERN, NIGERIA
}

\author{
OJURI 0.0. ${ }^{1}$ \\ TAIWO O.A. ${ }^{1}$ \\ OLUWATUYI O.E. ${ }^{2, *}$
}

\author{
${ }^{1}$ Department of Civil and Environmental Engineering \\ Federal University of Technology, Akure, Nigeria \\ ${ }^{2}$ Department of Civil Engineering \\ Landmark University, Omu-Aran, Kwara State, Nigeria
}

Received: $16 / 04 / 2016$

Accepted: 29/06/2016

Available online: $27 / 07 / 2016$

*to whom all correspondence should be addressed: e-mail: oluwatuyi.opeyemi@Imu.edu.ng

\begin{abstract}
This paper presents migration of some selected heavy metal (zinc, lead, copper, chromium and nickel) of roadside soil samples from llesa-Akure highway assessing the degree of contamination such soils contain and the likelihood that this contamination can be remobilized. Soil samples were collected from 5 locations (Ilesa, Ipetu-ijesa, JABU, Ilara-mokin and FUTA north gate) at depths of 0-5, 15-20, 35-40 and 55-60 cm and analysed for the five selected heavy metals in the bulk sample and clay fraction. Their concentrations and distributions in four different road verge zones $(5 \mathrm{~m}, 30 \mathrm{~m}, 60 \mathrm{~m}$ and $110 \mathrm{~m})$ were determined. The $5 \mathrm{~m}$ zone had the highest mean concentration of the five metals whereas the $110 \mathrm{~m}$ zone exhibited the lowest mean concentration. Zinc and lead exhibited a significant decrease in the roadside soils with the increasing distance from the road while chromium and nickel showed significant increase, copper on the other hand showed no significant difference. Quantitative assessment of the heavy metal contamination using the $I_{\text {geo }}$ and $P I$ indexes showed that the selected heavy metals were in the order of $\mathrm{Cu}<\mathrm{Pb}<\mathrm{Zn}<\mathrm{Ni}<\mathrm{Cr}$ for both Indexes. Soil characteristics (which include $\mathrm{pH}$, Cation exchange capacity $\{\mathrm{CEC}\}$, organic matter and other basic geotechnical tests) responsible for the mobility and vertical distributions of these heavy metals from the road side soil were also assessed.
\end{abstract}

Keywords: Clay Minerals, Geo-accumulation Index, Heavy Metals, Pollution Index, Roadside Soil, Soil Contamination

\section{Introduction}

Rural highway route baseline data is essential for assessing suburbanization and urban sprawl effects in a developing country like Nigeria. One of such baseline data is the quantity of heavy metal contamination and its migration on the roadway. Heavy metals contamination is a subject of continuous interest within the scientific community, due to the toxic effects on the entire biosphere (Varol, 2011). Anthropogenic activity is one of the most important sources of heavy metal pollution. Vehicular traffic is a human induced activity and a major source of contaminants released into the natural environment (Duong and Lee, 2011). The worldwide high vehicular traffic density has led to accelerated emission rates, causing contamination of roadside soils (Modrzewska and Wyszkowski, 2014 and Kummer et al., 2009). Heavy metals emitted from motor vehicles

Ojuri O.O., Taiwo O.A. and Oluwatuyi O.E. (2016), Heavy metal migration along a rural highway route: Ilesha-Akure roadside oil, Southwestern, Nigeria, Global NEST Journal, 18(4), 742-760. 
remain suspended in air and deposited along the roadside soil (Yu et al., 2014). Lead, chromium, copper, nickel and zinc are the major metal pollutants of the roadside environments and are released from fuel burning, wear out of tyres, leakage of oils, pavement degradation and corrosion of batteries and metallic parts such as radiators etc. (Rijkenberg and Depree, 2010; Wei et al., 2009; Nixon and Saphores, 2007 and Dolan et al., 2006). Roadside soils are important reservoirs for the direct pollution from vehicle sources, which could easily come in contact with pedestrians and people residing within the vicinity of the roads either as suspended dust or directly. The accumulation of heavy metals in soils can be a secondary source of water pollution in a transformed environmental condition (Cheung et al. 2003). Recently, street dusts and top roadside soils in urban areas are considered as indicators of heavy metal contamination from atmospheric deposition (Chen et al., 2010; Christoforidis and Stamatis 2009; Lee et al., 2005) and dusts (Al-Khashman 2004; Banerjee 2003; Lu et al., 2009; Omar et al., 2007).

The heavy metals can impair important biochemical processes posing a threat to human health, plant growth and animal life (Jarup 2003; Michalke 2003; Silva et al., 2005). Vertical distributions of heavy metals in soil has been well researched (Azeez et al., 2011) and are generally intended mainly for the estimation of the risk of contamination to soil, plants and groundwater quality (Adelekan et al., 2011). Notable methods of estimating heavy metal mobility in soils are the adsorption experiments (or batch tests) and the infiltration tests. However, heavy metals may chemically or physically interact with the natural compound, which changes their forms of existence in the environment. In general they may react with particular species, change oxidation states and precipitate (Dube et al., 2000). Heavy metals may be bound or sorbed by particular natural substances, which may increase or decrease mobility. Many soil chemical and biological reactions are controlled by the $\mathrm{pH}$ of the soil solution in equilibrium with the soil particle surfaces. In this study, attempt is only made to investigate the vertical migrations of heavy metals in soil (Iwegbue et al., 2010), with the view to elucidate the risk of contamination to the environment (Azeez et al., 2011). With increase in population and economic activities, this study constitutes a part of a broader research on the ecology and conservation of the roadside vegetation and life generally on llesa- Akure highway.

\section{Materials and Methods}

\subsection{Study Area}

The llesa- Akure road is a Federal government road. It is one of the many roads that link south west Nigeria to the south east part of the country. The highway is a two lane road designed to conform to the appropriate national standards in terms of load capacity, width and safety provision. The location was chosen as a study area because this research focuses on heavy metal pollution to roadside soil mainly due to transportation/ vehicular activities on the road. Also, the strategic geographical location of the road makes it an important route. The road lies within Osun and Ondo state. It is bounded in the west by Oyo and in the south by Edo state. The composition and volume of the vehicular traffic using the road comprises of heavy trucks, light weight vehicles, high speed and slow moving vehicles. The length of the study area is approximately $74 \mathrm{~km}$. Some of the local factors which influence traffic growth include agricultural and industrial development. Notable features along the road include higher institution of learning such as Joseph Ayo Babalola University (JABU), Ikeji Arakeji, Elizade University (EU), Ilara- mokin, Federal University of Technology, Akure (FUTA). Others include Owena Multipurpose dam and popular Owena market. Figure 1 shows a map of the study area and the various sampling locations along the road. 


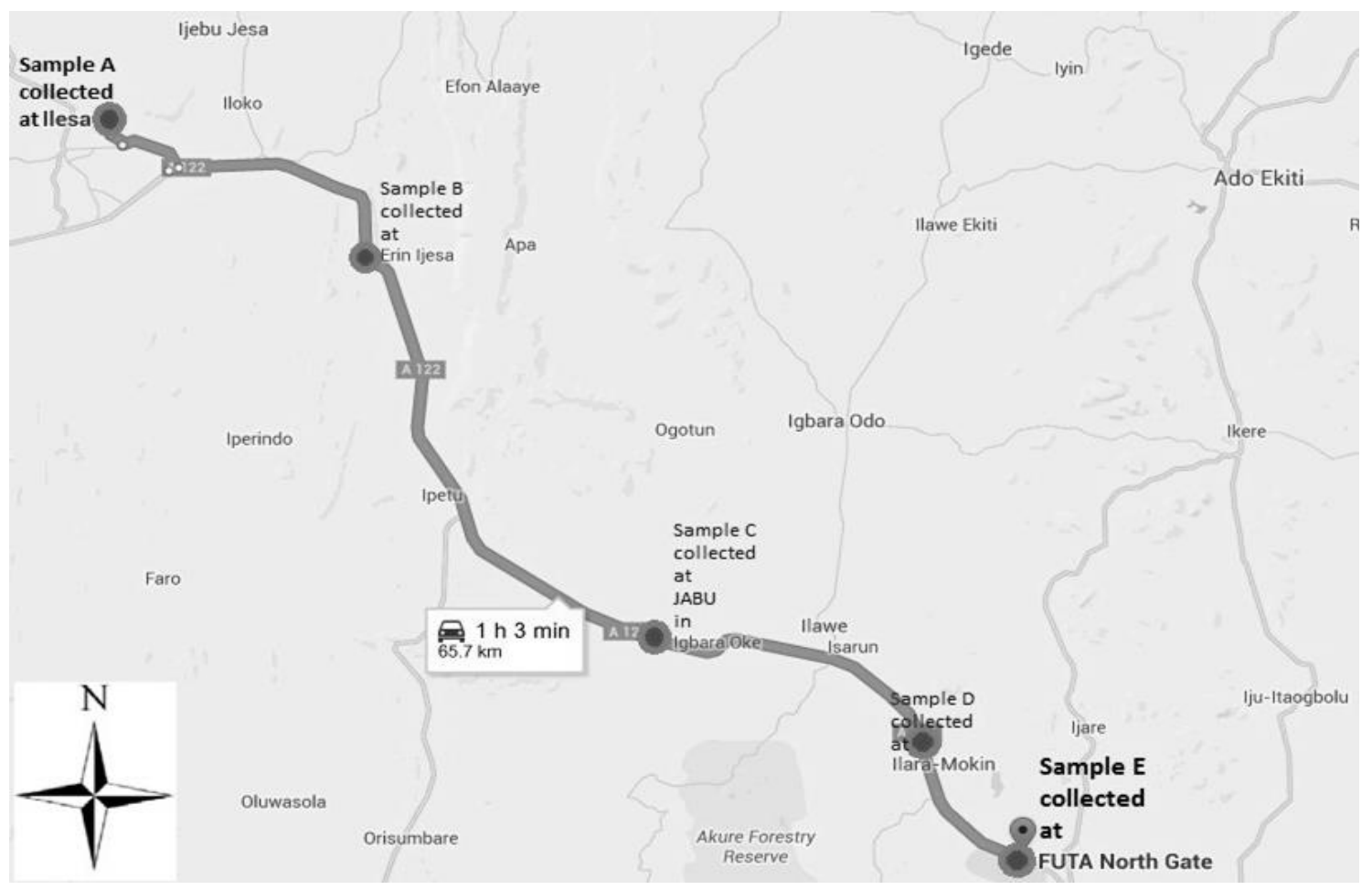

Figure 1. Location map of sampling site along the llesa-Akure road

\subsection{Collection of soil sample}

Forty composite soil samples were collected in a soil profile of roadside soil at five different locations, Table 1 shows the geographic coordinates for the five different sampling sites. In each site, four soil samples were collected in a soil profile at $5 \mathrm{~m}$ and another four were collect at $30 \mathrm{~m}$ away from the road pavement at a depth interval of $0-5 \mathrm{~cm}, 15-20 \mathrm{~cm}, 35-40 \mathrm{~cm}$ and $55-60 \mathrm{~cm}$ using stainless steel. Table 2 shows the sample labels for samples collected at each depth at different sampling locations. The stainless steel was used for sample collection to avoid cross contamination. The sampling period was during the dry season. After sampling, the soil samples were packed in different polythene bags and was well labeled and stored in readiness for laboratory analyses.

Table 1. Geographic Coordinates of sampling site

\begin{tabular}{cccc}
\hline S/N & Location & Latitude & Longitude \\
\hline $\mathbf{1}$ & Ilesa & $7^{0} 37.17^{1}$ & $4^{0} 49.29^{1}$ \\
\hline $\mathbf{2}$ & Ipetu ljesa & $7^{0} 30.84^{1}$ & $4^{0} 53.44^{1}$ \\
\hline $\mathbf{3}$ & JABU & $7^{0} 24.38^{1}$ & $5^{0} 01.17^{1}$ \\
\hline $\mathbf{4}$ & Ilara mokin & $7^{0} 20.53^{1}$ & $5^{0} 06.19^{1}$ \\
\hline $\mathbf{5}$ & Akure & $7^{0} 05.14^{1}$ & $5^{0} 21.85^{1}$ \\
\hline
\end{tabular}

Table 2. Sample labels according to the depth and location of sampling site

\begin{tabular}{cccccc}
\hline Depth/Location & ILESA (A) & IPETU (B) & JABU (C) & ILARA MOKIN (D) & AKURE (E) \\
\hline $\mathbf{0 - 5 c m ~ ( 1 ) ~}$ & A1 & B1 & C1 & D1 & E1 \\
\hline $\mathbf{1 5 - 2 0 c m ~ ( 2 ) ~}$ & A2 & B2 & C2 & D2 & E2 \\
\hline $\mathbf{3 5 - 4 0 c m ~ ( 3 ) ~}$ & A3 & B3 & C3 & D3 & E3 \\
\hline $\mathbf{5 5 - 6 0 c m ~ ( 4 ) ~}$ & A4 & B4 & C4 & D4 & E4 \\
\hline
\end{tabular}




\subsection{Determination of the Atterberg limits and Particle size distribution (Mechanical sieve and hydrometer method)}

The atterberg limit test was done in accordance to BS1377:1990 (Part 2:4\&5) while the particle size distribution was done in accordance to BS1377:1990 (Part 2:9)

\subsection{Determination of Cation Exchange Capacity (CEC)}

The CEC of a soil is the number of positive charges that a representative sample of soil can hold. It is usually described as the number of hydrogen ions necessary to fill the soil cation holding sites per 100 grams of dry soil. $10 \mathrm{~g}$ of air dry soil was transferred into a $250 \mathrm{ml}$ beaker and $100 \mathrm{ml}$ of $\mathrm{NH}_{4} \mathrm{OAc}$ was added. After 12-15 hours, the content was transferred to the Buchner flask and filter paper with the aid of suction pump. The leachate was collected to make $100 \mathrm{ml}$ with $\mathrm{NH}_{4} \mathrm{OAc}$. The soil residue was washed by leaching with $100 \mathrm{ml}$ $95 \%$ ethanol to remove $\mathrm{NH}_{4}^{+}$. The soil was also leached with $100 \mathrm{ml}$ of $1 \mathrm{M} \mathrm{NaCl}$ into a $100 \mathrm{ml}$ volumetric flask. $\mathrm{NH}_{4}{ }^{+}$in the leachate was measured by distillation on a Markham distiller.

\subsection{Determination of the Organic Matter Content}

The bulk sample was dried in the oven at $105^{\circ} \mathrm{C}$, weighed to the nearest $0.1 \%$ of the mass recorded. Soil sample was grinded to a fine powder and $1.0 \mathrm{~g}$ of soil sample was transferred to $250 \mathrm{ml}$ conical flask in duplicate. $10 \mathrm{ml}$ of $0.167 \mathrm{M} \mathrm{K}_{2} \mathrm{Cr}_{2} \mathrm{O}_{7}$ was added to it. Also, $20 \mathrm{ml}$ conc. $\mathrm{H}_{2} \mathrm{SO}_{4}$ was rapidly added. The flask was stirred until the soil and the reagents were mixed for about 30 minutes. $100 \mathrm{ml}$ of distilled water was added and about 4 drops of ferroin indicator was titrated with $0.5 \mathrm{M}$ Iron (11) ammonium sulphate. The solution takes a greenish cast and then changes to dark green. At this point, ferrous sulphate was added drop by drop until the colour changed sharply from green to brownish red. Blank titration was made in the same manner to standardize the iron (11) solution.

\subsection{Determination of $\mathrm{pH}$}

A little quantity of Barium - sulphate was added into a test tube. And a quantity of soil which has been sieved through $2 \mathrm{~mm}$ sieve was added to the solution. Distilled water was added to reach the lower mark, while soil indicator was also added to reach the upper mark. The upper end of the test tube was closed with a cork and the mixture was stirred. After 30 minutes the $\mathrm{pH}$ was determined by carefully comparing the solution with the standard chart with each colour carrying its corresponding $\mathrm{pH}$ value.

\subsection{Determination of Heavy Metals Concentration}

Heavy metals $(\mathrm{Zn}, \mathrm{Pb}, \mathrm{Cr} \mathrm{Cu}$, and $\mathrm{Ni}$ ) were analyzed by Inductively Coupled Plasma Atomic Emission Spectrometry (ICP -AES). For elemental analysis, the samples require digestion and this was carried out as follows. The sample was dried to $105^{\circ} \mathrm{C}$, and a representative of $0.5 \mathrm{ml} / 5 \mathrm{~g}$ homogenized soil sample was mixed with $0.5 \mathrm{ml} / 5 \mathrm{ml}$ of finely ground potassium permanganate/ $\mathrm{HNO}_{3}$ and then $1.0 \mathrm{ml}$ of concentrated sulfuric acid was added and vigorously stirred at $3000 \mathrm{rev} / \mathrm{min}$ while a strong exothermic reaction occurred. The sample was then treated with $2 \mathrm{ml}$ concentrated nitric acid. Also, $10 \mathrm{ml}$ of concentrated Hydrofluoric acid was added and the sample heated until the reaction was completed and was then filtered. The filter paper was washed with hot $\mathrm{HCl}$ and the filter paper was transferred to a digestion flask. The solution was topped with distilled water and was shaken well. This solution was then analyzed with AAS. Standard procedures for the preparation of these metals were employed. The sample was brought to volume and analyzed. Light with specific frequencies was absorbed by different metals when they vaporize in a flame moving them from their ground state to a higher energy state. The hollow cathode lamp provided the emission of the element, with every element having its own wavelength. The amount of light absorbed was proportional to the concentration of the metal in solution. The amount of light absorbed by the sample was compared to the amount of light absorbed by a set of standard of known concentration. 
For samples of the clay fraction, after crushing of the samples in an agate mortar, $4 \mathrm{~g}$ of sample was dried at $110{ }^{\circ} \mathrm{C}$, and then burned at $1000{ }^{\circ} \mathrm{C}$ for 3 hours. Then, the suspension underwent a washing with distilled water to eliminate the excess of $\mathrm{H}_{2} \mathrm{O}_{2}$ (35\%). The suspension was centrifuged at $3000 \mathrm{rev} / \mathrm{min}$ for $10 \mathrm{~min}$. After washing, the base of centrifugation was suspended using mixer. This suspension was poured in a bottle and $100 \mathrm{ml}$ of distilled water was added. Separation of the clay fractions $(<2 \mu \mathrm{m})$ were performed by sedimentation in aqueous suspension. After a time of sedimentation of about 2 hours, the upper $2 \mathrm{~cm}$ of the suspension was siphoned and correspond to the fraction $<2 \mathrm{~mm}$. The clay fraction $(<2 \mathrm{~mm})$ was centrifuged at $3500 \mathrm{rev} / \mathrm{min}$ for $40 \mathrm{~min}$. Total and soluble metals concentrations was determined by air-acetylene flame $\mathrm{(Cu})$ and graphite furnace $(\mathrm{Pb}, \mathrm{Cd})$ atomic absorption spectrophotometry employing background correction facilities to eliminate all non-specific absorption (Perkin-Elmer, ANALYST-100). External standards prepared in the corresponding extraction solution were used for calibration for each extract. Statistical evaluation was applied in data analyzing study.

The geo-accumulation index ( $\left.I_{g e o}\right)$ and pollution index (PI) (Radziemska and Fronczyk, 2015) were calculated and used to assess the contamination degrees of heavy metals for the study region. The $I_{\text {geo }}$ was calculated by Equation (1) and the $P I$ using equation (2). The classification of soil contamination using $I_{\text {geo }}$ and $P I$ indexes is presented in Table 3. Data were also subjected to a one-way analysis of variance (ANOVA) by SPSS software (version 16.0) to determine the differences in the concentration of each heavy metal between depths and distance from road, possibilities less than 0.05 were considered significant.

$$
\begin{aligned}
& \mathrm{I}_{\text {geo }}=\log _{2}\left[\frac{\mathrm{C}_{\mathrm{n}}}{1.5 \mathrm{~B}_{\mathrm{n}}}\right] \\
& \mathrm{PI}=\frac{\mathrm{C}_{\mathrm{n}}}{\mathrm{B}_{\mathrm{n}}}
\end{aligned}
$$

Where $C_{n}$ is the measured concentration of the metal $n$ and $B_{n}$ is the geochemical background value of the metal. Since this study is the first of its kind for llesha-Akure roadside soil, there is no local information in literature available for comparison as the geochemical background value of the metals. Data reported here were therefore used to examine the extent of contamination by $\mathrm{Zn}, \mathrm{Pb}, \mathrm{Cu}, \mathrm{Cr}$, and $\mathrm{Ni}$ using comparable pristine samples obtained at least $0.5 \mathrm{~km}$ from the roadside sampled sites.

Table 3. Soil pollution degrees based on $I_{g e o}$ and PI. (Adapted from Radziemska and Fronczyk, 2015)

\begin{tabular}{ccccc}
\hline $\mathbf{I}_{\text {geo }}$ & $\mathbf{I}_{\text {geo }}$ Class & Pollution Category & PI & Pollution Category \\
\hline $\mathrm{I}_{\text {geo }} \leq 0$ & 0 & Uncontaminated & $\leq 0$ & Low \\
\hline $0<$ Ieo $_{\text {geo }} \leq 1$ & 1 & Uncontaminated to moderately contaminated & $1-3$ & Middle \\
\hline $1<$ geo $_{\text {ge }} \leq 2$ & 2 & Moderately contaminated & $>3$ & High \\
\hline $2<$ geo $_{\text {ge }} \leq 3$ & 3 & Moderately to strongly contaminated & & \\
\hline $3<\left.\right|_{\text {geo }} \leq 4$ & 4 & Strongly contaminated & & \\
\hline $4<\left.\right|_{\text {geo }} \leq 5$ & 5 & Strongly to extremely contaminated & & \\
\hline$I_{\text {geo }} \geq 5$ & 6 & Extremely contaminated & & \\
\hline
\end{tabular}

\section{Results and Discussion}

\subsection{Results of Geotechnical properties}

The results of basic geotechnical tests which include the atterberg limit test and particle size distribution are presented in Table 4 and Figures 2-6 respectively. 
Table 4. Summary of Atterberg Limit tests

\begin{tabular}{cccccccc}
\hline $\begin{array}{c}\text { Site } \\
\text { Description }\end{array}$ & $\begin{array}{c}\text { Liquid } \\
\text { limit } \\
\mathbf{( \% )}\end{array}$ & $\begin{array}{c}\text { Plastic } \\
\text { limit } \\
\mathbf{( \% )}\end{array}$ & $\begin{array}{c}\text { Plasticity } \\
\text { Index } \\
\mathbf{( \% )}\end{array}$ & $\begin{array}{c}\text { Site } \\
\text { Description }\end{array}$ & $\begin{array}{c}\text { Liquid limit } \\
\text { (\%) }\end{array}$ & $\begin{array}{c}\text { Plastic } \\
\text { limit (\%) }\end{array}$ & $\begin{array}{c}\text { Plasticity } \\
\text { Index (\%) }\end{array}$ \\
\hline Al & 45 & 30 & 15 & C3 & 36 & 23 & 13 \\
\hline A2 & 41 & 27 & 14 & C4 & 31 & 23 & 8 \\
\hline A3 & 36 & 23 & 13 & D1 & 51 & 33 & 18 \\
\hline A4 & 32 & 20 & 12 & D2 & 50 & 30 & 20 \\
\hline B1 & 44 & 31 & 13 & D3 & 42 & 29 & 13 \\
\hline B2 & 43 & 29 & 14 & D4 & 35 & 24 & 11 \\
\hline B3 & 35 & 22 & 13 & E1 & 60 & 39 & 21 \\
\hline B4 & 30 & 20 & 10 & E2 & 59 & 37 & 22 \\
\hline C1 & 40 & 25 & 15 & E3 & 48 & 34 & 14 \\
\hline C2 & 38 & 26 & 12 & E4 & 38 & 29 & 9 \\
\hline
\end{tabular}

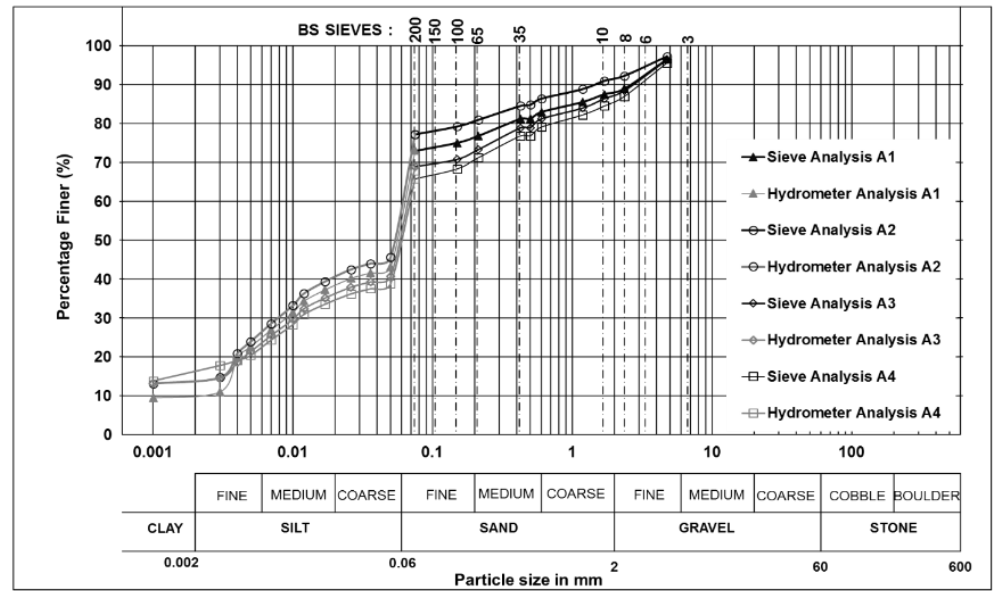

Figure 2. Particle size distribution curve for soil sample taken at llesa at different depths

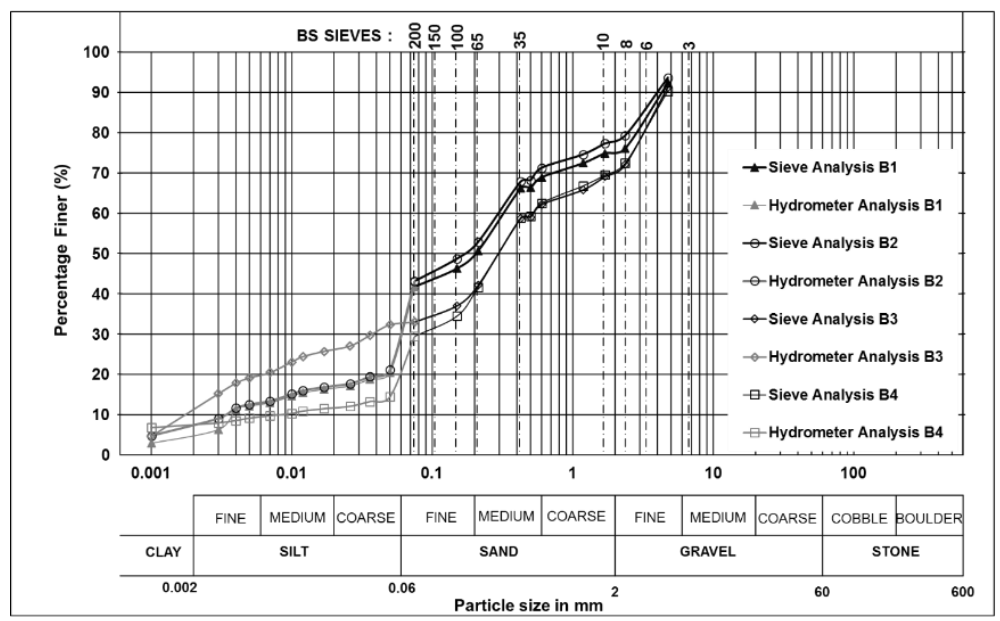

Figure 3. Particle size distribution curve for soil sample taken at Ipetu-ijesa at different depths 


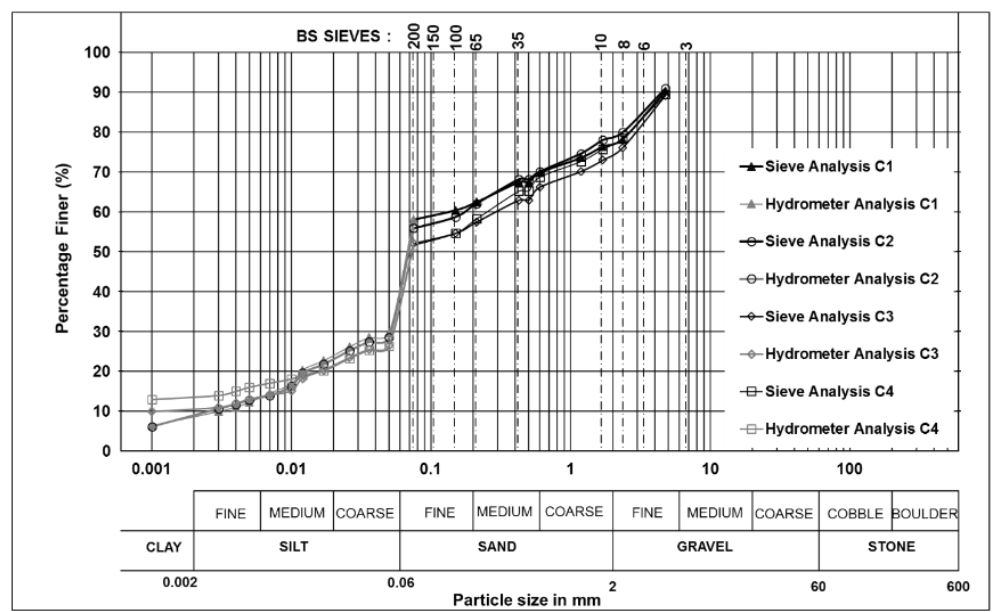

Figure 4. Particle size distribution curve for soil sample taken at JABU at different depths

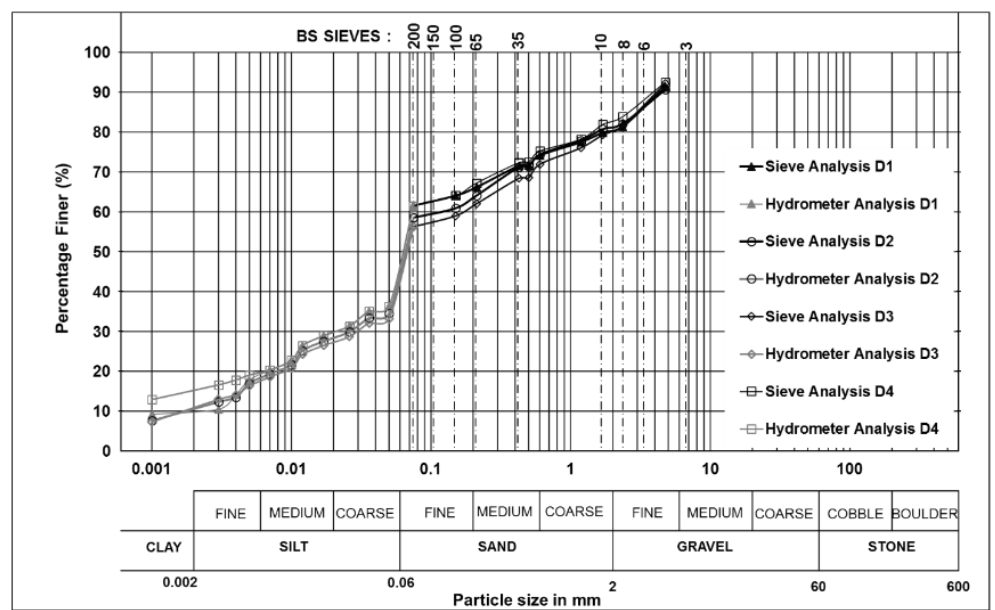

Figure 5. Particle size distribution curve for soil sample taken at llara-mokin at different depths

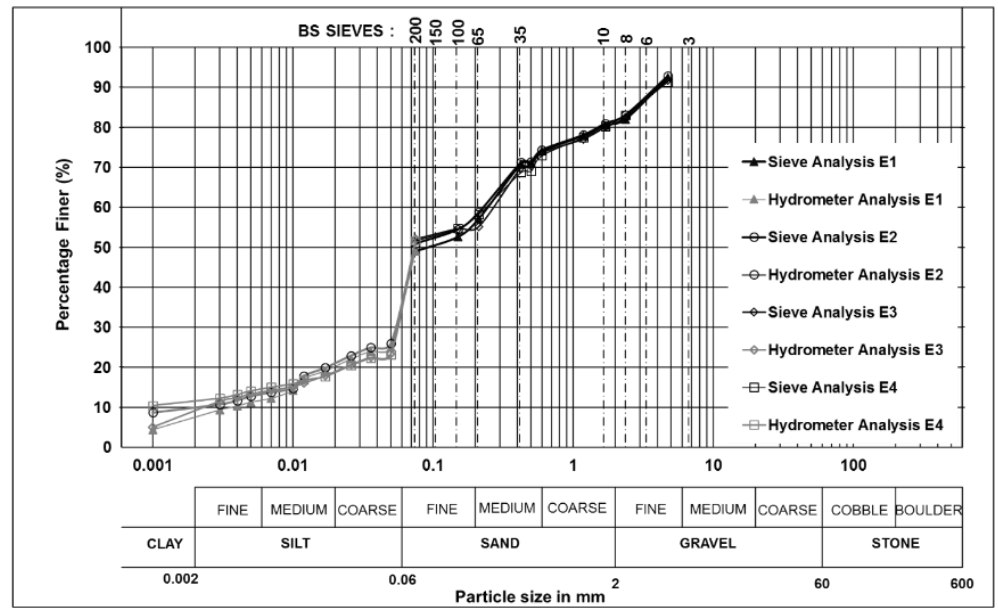

Figure 6. Particle size distribution curve for soil sample taken at FUTA at different depths 
The percentage clay fraction of particle size in the soil samples were in the range of 13.89 to 26.31 . Generally, the geotechnical properties of all the soil samples showed that highest value of LL was $60 \%$, while the lowest was $30 \%$. The values of PL ranged between $20 \%$ and $39 \%$. The difference in moisture content between the liquid limit (LL) and plastic limit (PL) gave the plasticity index (PI) value in the range of 8 to $22 \%$. The Akurellesa highway route is underlain by clays, sandy clays, clayey sands, sands and laterites occurring at varying depths and locations along the route. The Atterberg limits was used for predicting activity of clay. The plasticity of a given soil depends upon the nature of the clay mineral, the type of the clay mineral present in the soil sample (whether it is Kaolinite or Montmorillonite or Illite) and the amount of the clay mineral present. The activity of the clay from the samples collected in this study ranges from 0.30 to 1.38 . This indicated that the minerals present in all the sites included kaolinite and illite in greater amount. Illite with an activity values from 0.5 to 1.3 was more present in the first three layers $(0-5,15-20$ and $35-40 \mathrm{~cm})$. Kaolinite with an activity values from 0.3 to 0.5 was more abundant at depth $55-60 \mathrm{~cm}$ in all the sampled sites. The overall negative charge on this clay mineral due to isomorphous substitution could have attracted the positive charges of these heavy metals.

\subsection{Results of Physicochemical properties}

Results of the physicochemical analysis (which include $\mathrm{pH}$, organic matter and cation exchange capacity) conducted on the soil samples from the five different sampling sites (Ilesa, Ipetu-ijesa, JABU, Ilara-mokin and FUTA north gate) at different depths $(0-5 \mathrm{~cm}, 15-20 \mathrm{~cm}, 35-40 \mathrm{~cm}, 55-60 \mathrm{~cm})$ for each sampling site on the llesaAkure Highway is presented in Table 5. The Adjusted mean for each depths were calculated using the SPSS software from the different sampling sites as shown in Table 5.

Table 5. Chemical properties of the soil samples showing their adjusted mean $( \pm \sigma)$

\begin{tabular}{cccc}
\hline DEPTH $(\mathbf{c m})$ & $\mathbf{p H}$ & $\mathbf{O M}\left(\mathbf{g ~ k g}^{-1}\right)$ & CEC $\left(\mathbf{c m o l ~} \mathbf{~ g g}^{-1}\right)$ \\
\hline $0-5$ & $3.48 \pm 0.52$ & $9.97 \pm 3.46$ & $7.61 \pm 1.34$ \\
\hline $15-20$ & $4.19 \pm 0.40$ & $7.11 \pm 1.26$ & $11.37 \pm 2.33$ \\
\hline $35-40$ & $4.30 \pm 0.32$ & $5.93 \pm 0.93$ & $13.90 \pm 1.78$ \\
\hline $55-60$ & $4.94 \pm 1.04$ & $0.49 \pm 0.26$ & $15.29 \pm 2.01$ \\
\hline
\end{tabular}

OM- Organic Matter CEC- Cation Exchange Capacity

From Table 5, the $\mathrm{pH}$ result indicated that the soil samples were slightly acidic with values in the range 3.48 to 4.94. Soil pH serves as a useful index of availability of nutrients, the potency of toxic substances present in the soil as well as the physical properties of the soil. Several studies have shown that availability of heavy metals is $\mathrm{pH}$ dependent and their mobility in soil decreases with increased soil pH and vice versa (GonzalezFernandez et al., 2008). Availability of $\mathrm{Cd}$ and $\mathrm{Zn}$ to the roots of Thlaspi caerulescens decreased with increases in soil pH (Wang et al., 2006).

The soil organic matter content was found to be in the range of 9.97 to $0.49 \mathrm{~g} \mathrm{~kg}^{-1}$ across the sample locations. The presence of organic matter has a significant effect on the mobility and bioavailability of heavy metals (De la Rosa et al., 2003). Organic matter have been shown to decrease heavy metal availability through immobilization of these metals (Yi et al., 2007). Furthermore, it has also been reported that about $50 \%$ of the total heavy metals in organic rich soils are retained with organic substances (Smagunova et al., 2004), but these values across the locations does not give an indication of a high tendency of heavy metals availability and retention in the soils. Organic matter content, however, decreases with depth, so that the mineral constituents of soil will become a more important surface for sorption as the organic matter content of the soil diminishes.

The Cation exchange capacity (CEC) is $\mathrm{pH}$ dependent in all the soil profile. They were found to be in the range of 7.61 to $15.29 \mathrm{cmol} \mathrm{kg}^{-1}$. CEC is used as a measure of soil fertility, nutrient retention capacity, and the capacity to protect groundwater from cation contamination. From the results in Table 5, CEC were mainly 
abundant in the profiles 3 (depth $35-40 \mathrm{~cm}$ ) and 4 (depth $55-60 \mathrm{~cm}$ ). It was also found in little amounts in the topsoil $(0-5 \mathrm{~cm})$ all the soil samples investigated.

\subsection{Results of Heavy metals distribution}

The results of the selected heavy metal distribution on the llesa-Akure roadside soils (for both the bulk sample and clay sample) at all depths with respect to distance from the road is presented in Table 6. Table 7, shows the target and intervention values for the selected heavy metals as provided by the department of petroleum resources in Nigeria.

Table 6. Concentration of selected heavy metals in roadside soils at all depths with respect to distance from the road

\begin{tabular}{ccccccc}
\hline & \multicolumn{7}{c}{ Bulk Sample (Mean $\pm \boldsymbol{\sigma}$ ) } & \multicolumn{3}{c}{ Clay Fraction (Mean $\pm \sigma$ ) } \\
\hline Metal & Min & Max & Mean $\pm \boldsymbol{\sigma}$ & Min & Max & Mean $\pm \sigma$ \\
\hline Zinc & 34.80 & 74.88 & $51.56 \pm 12.26$ & 53.29 & 125.04 & $83.66 \pm 20.58$ \\
\hline Lead & 0.79 & 2.40 & $1.54 \pm 0.41$ & 0.49 & 1.35 & $0.82 \pm 0.25$ \\
\hline Chromium & 6.11 & 13.58 & $9.43 \pm 2.25$ & 23.34 & 66.95 & $42.06 \pm 12.18$ \\
\hline Copper & 8.70 & 18.72 & $12.97 \pm 3.08$ & 15.28 & 41.83 & $25.61 \pm 7.02$ \\
\hline Nickel & 1.36 & 8.61 & $4.49 \pm 1.87$ & 3.67 & 32.83 & $17.10 \pm 8.64$ \\
\hline & & \multicolumn{5}{c}{$\mathbf{3 0 m}$ from roadside } \\
\hline Metal & Min & Max & Mean $\pm \sigma$ & Min & Max & Mean $\pm \sigma$ \\
\hline Zinc & 8.15 & 33.22 & $21.21 \pm 7.70$ & 17.00 & 42.30 & $28.10 \pm 7.90$ \\
\hline Lead & 0.53 & 1.64 & $1.00 \pm 0.27$ & 0.20 & 0.87 & $0.49 \pm 0.19$ \\
\hline Chromium & 1.13 & 9.51 & $5.03 \pm 2.90$ & 10.89 & 33.01 & $20.96 \pm 6.20$ \\
\hline Copper & 1.14 & 8.21 & $5.24 \pm 1.77$ & 5.34 & 20.81 & $12.03 \pm 3.77$ \\
\hline Nickel & 0.20 & 4.86 & $1.49 \pm 1.36$ & 0.88 & 15.28 & $4.92 \pm 4.57$ \\
\hline
\end{tabular}

Table 7. Target and intervention values for some soil heavy metals provided by the Department of Petroleum Resources (DPR-EGASPIN, 2002)

\begin{tabular}{ccc}
\hline Metal & Target value (ppm) & Intervention value (ppm) \\
\hline Zn & 150.00 & 1000.00 \\
\hline $\mathbf{P b}$ & 35.00 & 210.00 \\
\hline $\mathbf{C r}$ & 20.00 & 240.00 \\
\hline $\mathbf{C u}$ & 0.30 & 10.00 \\
\hline $\mathbf{N i}$ & 140.00 & 720.00 \\
\hline
\end{tabular}

In order to determine if the differences in the heavy metal concentration observed between the different distances from the road and the different depths at which the samples were collected were significant, a statistical program (SPSS) was used to construct a general linear model of the data. A P-value of $p \leq 0.05$ (or $95 \%$ confidence) was selected to determine if the means of the heavy metals concentrations from each distance from the road or at each depth were significantly different from each other. According to the general linear model all the heavy metals significantly decreased $(p \leq 0.05)$ with regard to distance from the road.

Soils collected nearest to the road $(5 \mathrm{~m})$ were characterized by the highest contents of the analyzed heavy metals, the concentration of which decreased the further the soil was from the expressway. The relationship between the physiochemical properties ( $\mathrm{pH}$, Organic Matter [OM] and Cation Exchange Capacity [CEC]) and heavy metal were also evaluated by Spearman's rank correlation coefficient, and the results are presented in Table 8. 
Table 8. Correlation coefficient between concentrations of metals and the physiochemical properties at the four different depths of sampling.

\begin{tabular}{|c|c|c|c|c|c|c|c|c|}
\hline & $\mathrm{Zn}$ & $\mathrm{Pb}$ & $\mathrm{Cr}$ & $\mathrm{Cu}$ & $\mathrm{Ni}$ & $\mathrm{pH}$ & OM & CEC \\
\hline $\mathrm{Zn}$ & 1 & & & & & & & \\
\hline $\mathrm{Pb}$ & $0.976^{*}$ & 1 & & & & & & \\
\hline $\mathrm{Cr}$ & $-0.998^{* *}$ & $-0.986^{*}$ & 1 & & & & & \\
\hline $\mathrm{Cu}$ & $0.991^{* *}$ & $0.995^{* *}$ & $-0.994^{* *}$ & 1 & & & & \\
\hline $\mathrm{Ni}$ & $-0.999^{* *}$ & $-0.986^{*}$ & $0.999^{* *}$ & $-0.997^{* *}$ & 1 & & & \\
\hline $\mathrm{pH}$ & $-0.963^{*}$ & $-0.978^{*}$ & $0.963^{*}$ & $-0.985^{*}$ & $0.974^{*}$ & 1 & & \\
\hline OM & $0.979^{*}$ & 0.944 & $-0.967^{*}$ & $0.971^{*}$ & $-0.978^{*}$ & $-0.974^{*}$ & 1 & \\
\hline CEC & $-0.954^{*}$ & $-0.995^{* *}$ & $0.969^{*}$ & $-0.980^{*}$ & $0.966^{*}$ & $0.957^{*}$ & -0.906 & 1 \\
\hline
\end{tabular}

*. Correlation is significant at the 0.05 level (2-tailed).

**. Correlation is significant at the 0.01 level (2-tailed).

Table 8 showed that all the metal pairs have strong correlations (both positive and negative) with each other. Strong positive correlations (for example between nickel and chromium, copper and zinc, copper and lead) indicates positive linear relationship which signify that each paired metals have common contamination sources. Relationship between the physicochemical properties and metals also had strong correlations (both positive and negative) with each other. Relationship between the heavy metal distribution and physiochemical properties showed that the distribution of heavy metals through the soil depths were affected by the soil's physiochemical properties with the exception of nickel and chromium. For $\mathrm{pH}$ and $\mathrm{CEC}$, nickel and chromium had a positive correlation as against the negative correlation prescribed by GonzalezFernandez et al, (2008) and for the Organic Matter, nickel and chromium had a negative correlation as against the positive correlation prescribed by Yi et al, (2007). This may be because the movement of nickel and chromium is not significantly affected by the $\mathrm{pH}$ value (one of the physiochemical properties) of the soil (Taseli et $a l, 2008$ ) or due to the soil texture and the source of this heavy metals in the soil.

\subsubsection{Zinc $(Z n)$}

The amount of zinc in the roadside soils ranged from 34.80 to $74.88 \mathrm{ppm}$ with the mean value of $51.56 \mathrm{ppm}$ in the bulk sample at $5 \mathrm{~m}$ from roadside. At $30 \mathrm{~m}$ from roadside, the concentration ranges from 8.15 to 33.22 ppm with mean value of $21.21 \mathrm{ppm}$ in the bulk sample (Table 6). The clay fraction of the sample on the other hand showed higher amount of zinc with the mean values of $83.66 \mathrm{ppm}$ at $5 \mathrm{~m}$ from the roadside and $28.10 \mathrm{ppm}$ at $30 \mathrm{~m}$ from the roadside, this shows that the clay fraction of the sample has a high adsorption capacity for zinc. These values were lower than the mean value of $108.6 \mathrm{ppm}$ reported by Achi et al (2008), lower than the permissible value of 100 ppm from the European standard (Romanian Guideline, 1997) and also lower than the target and intervention values provided by Nigeria Department of Petroleum Resources (Egaspin, 2002) as shown in Table 7.

Figure 7a shows the mean with standard deviation bars of zinc concentration for bulk and clay sample for $5 \mathrm{~m}$ and $30 \mathrm{~m}$ from the roadside. Figure $7 \mathrm{~b}$ showed a picture of further vertical migration for $60 \mathrm{~m}$ and $110 \mathrm{~m}$ from the roadside. Both Figures $7 a$ and $b$ showed that as the distance from the road increases, there was a decrease in the metal concentration. Also as the soil sampling depth increases, the zinc concentration level decreases down the soil profile. This was in agreement with the result obtained by Matini et al, (2011). The mean concentration of zinc at depth range of $0-5 \mathrm{~cm}$ was significantly greater than the mean concentration of zinc for depth range of $15-20 \mathrm{~cm}$. The mean concentration of zinc for depth range of $15-20 \mathrm{~cm}$ was significantly greater than that of the depth range for $35-40 \mathrm{~cm}$ and finally the mean concentration of zinc for the depth range of $35-40 \mathrm{~cm}$ was significantly greater than the mean concentration for the depth range of $55-60 \mathrm{~cm}$. Hence there was a significant $(P \leq 0.05)$ decrease in the zinc content with regard to depth down the soil profile. 


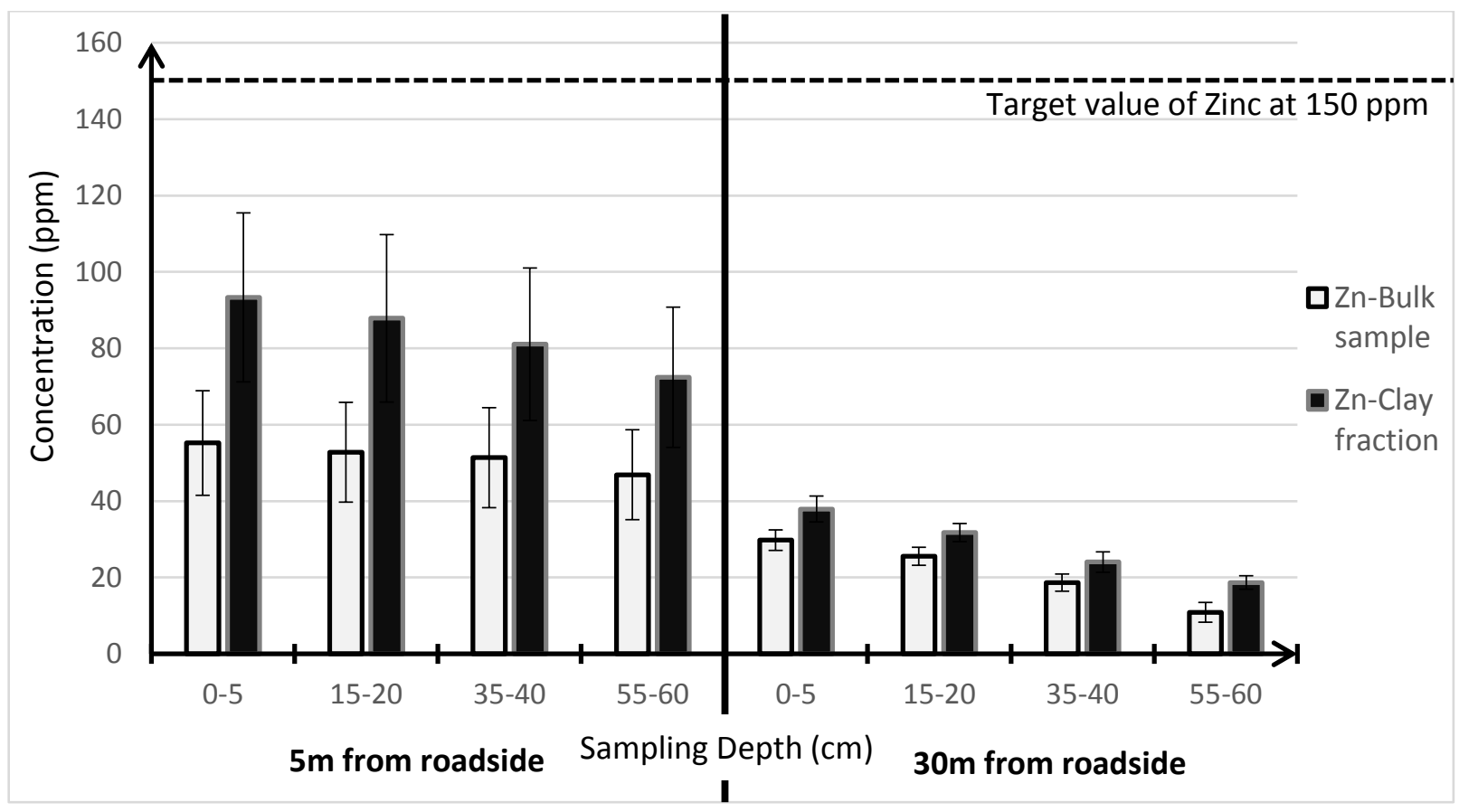

Figure 7a. Mean concentration of zinc with standard deviation error bars for bulk sample and clay fraction in roadside soil along llesa-Akure road with respect to depth and distance

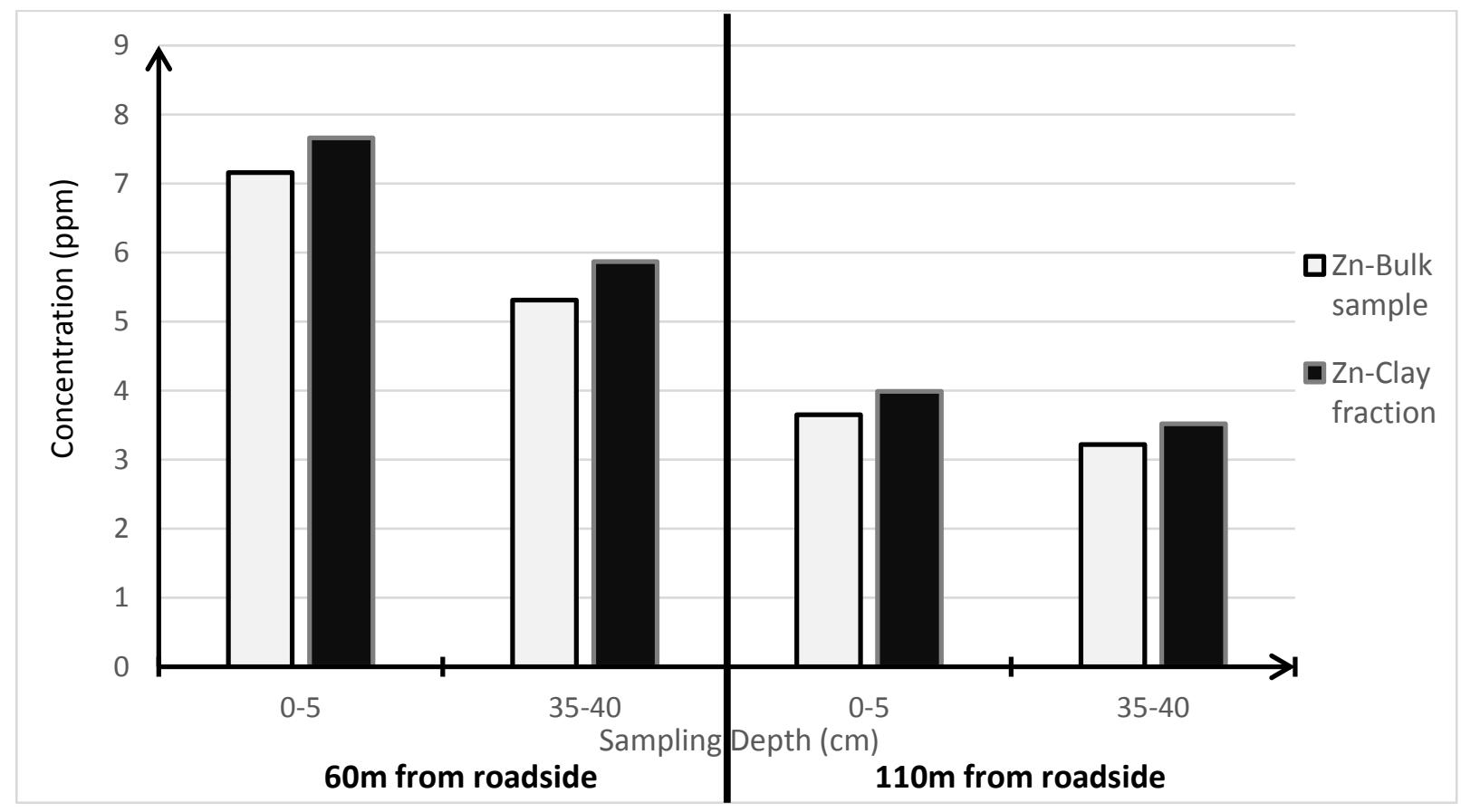

Figure $7 \mathrm{~b}$. Vertical distribution of zinc in the bulk and clay samples at $60 \mathrm{~m}$ and $110 \mathrm{~m}$ from the roadside

\subsubsection{Lead $(P b)$}

The amount of lead in the roadside soils ranged from 0.79 to $2.40 \mathrm{ppm}$ with the mean value of $1.54 \mathrm{ppm}$ in the bulk sample at $5 \mathrm{~m}$ from roadside. At $30 \mathrm{~m}$ from roadside, the concentration ranges from 0.53 to 
$1.64 \mathrm{ppm}$ with mean value of $1.00 \mathrm{ppm}$ in the bulk sample (Table 6). The clay fraction of the sample on the other hand showed lower amount of lead with the mean values of $0.82 \mathrm{ppm}$ at $5 \mathrm{~m}$ from the roadside and $0.49 \mathrm{ppm}$ at $30 \mathrm{~m}$ from the roadside, this was in agreement with the lead results from Matini et al, (2011) (although this changed when the distance from roadside was increased to 60 and $110 \mathrm{~m}$ ). The most probable source of lead in the road is the lead particulate matter emitted from gasoline vehicles which settles not far from the highway. Although the lead content in gasoline is minimized these days (which is somewhat visible from the results), increase in traffic will lead to an increase in lead emission in the roadside environments (Jones et al., 1991). These values were in range with the values reported by Warren and Birch (1987). The concentrations in all the sampled locations were lower than the permissible value of $20 \mathrm{ppm}$ and the alert level of 50 ppm from the European standards (Romanian Guideline, 1997). Also, the concentrations were also far below the target value of $35 \mathrm{ppm}$ and that of the value $210 \mathrm{ppm}$ intervention values by the Department of Petroleum Resources (EGASPIN, 2002) as shown in Table 7.

Figure 8a shows the mean with standard deviation bars of lead concentration for bulk and clay sample for $5 \mathrm{~m}$ and $30 \mathrm{~m}$ from the roadside. Figure $8 \mathrm{~b}$ showed a picture of further vertical migration by $60 \mathrm{~m}$ and $110 \mathrm{~m}$ from the roadside with the lead concentration of the clay fraction higher than that of the bulk sample, which unlike the $5 \mathrm{~m}$ and $30 \mathrm{~m}$ from the roadside whose clay fraction had a lower lead concentration than the bulk sample. Both Figures $8 a$ and $b$ showed that as the distance from the road increases, there was a decrease in the metal concentration, however study shows that lead contamination of soil may reach $100 \mathrm{~m}$ from the main road (Banerjee, 2003). Also as the soil sampling depth increases, the lead concentration level decreases down the soil profile. This was in agreement with the result obtained by Matini et al (2011). The mean concentration of lead at depth range of $0-5 \mathrm{~cm}$ was greater (but not significant) than the mean concentration of lead at depth range of $15-20 \mathrm{~cm}$. The mean concentration of lead at depth range of $0-5 \mathrm{~cm}$ was significantly greater than the mean concentration of lead for depth range of $35-40 \mathrm{~cm}$ and also significantly greater than the mean concentration of lead depth range of $55-60 \mathrm{~cm}$. Hence there was a significant $(P \leq 0.05)$ decrease in the lead content with regard to depth down the soil profile.

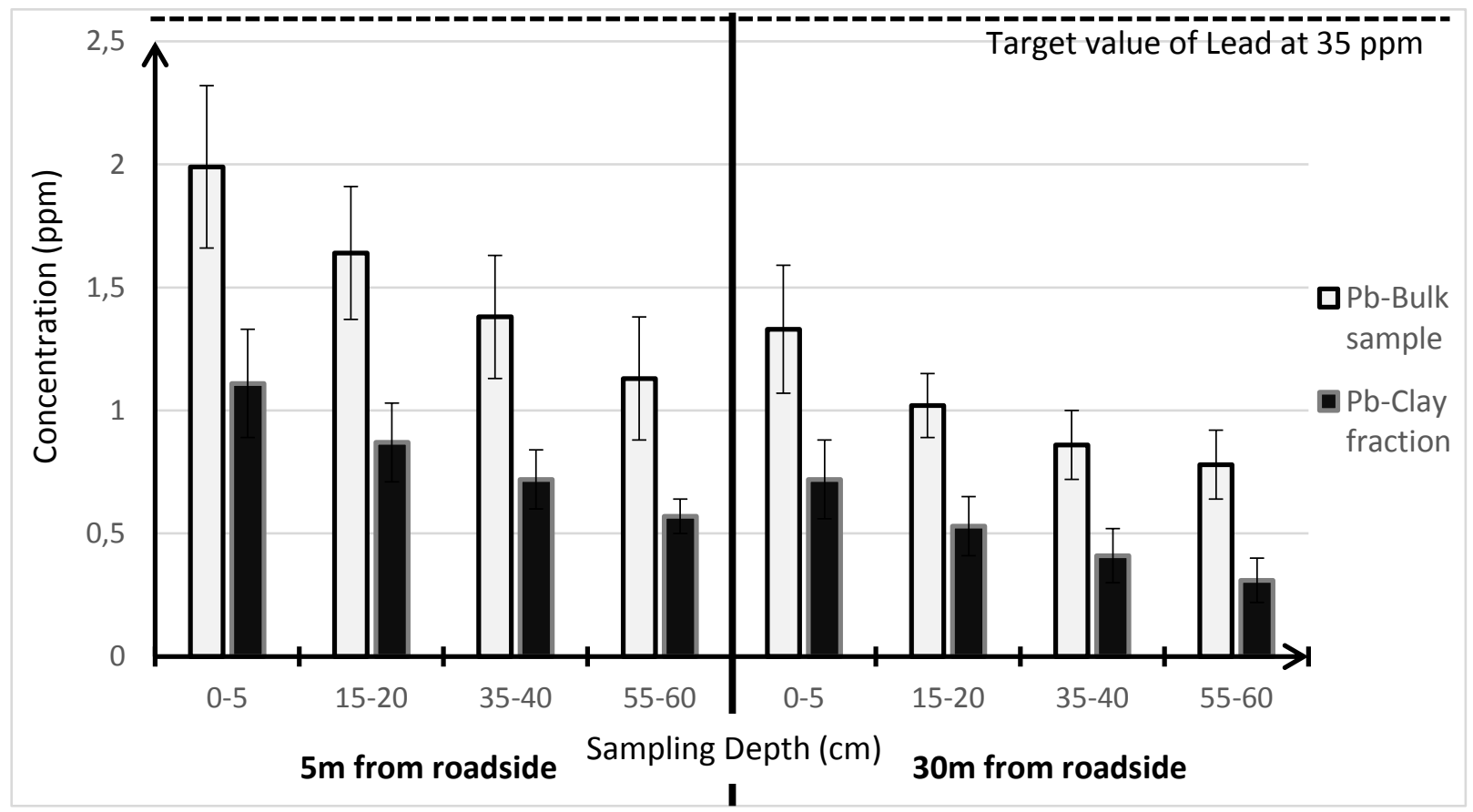

Figure 8a. Mean concentration of lead with standard deviation error bars for bulk sample and clay fraction in roadside soil along llesa-Akure road with respect to depth and distance 


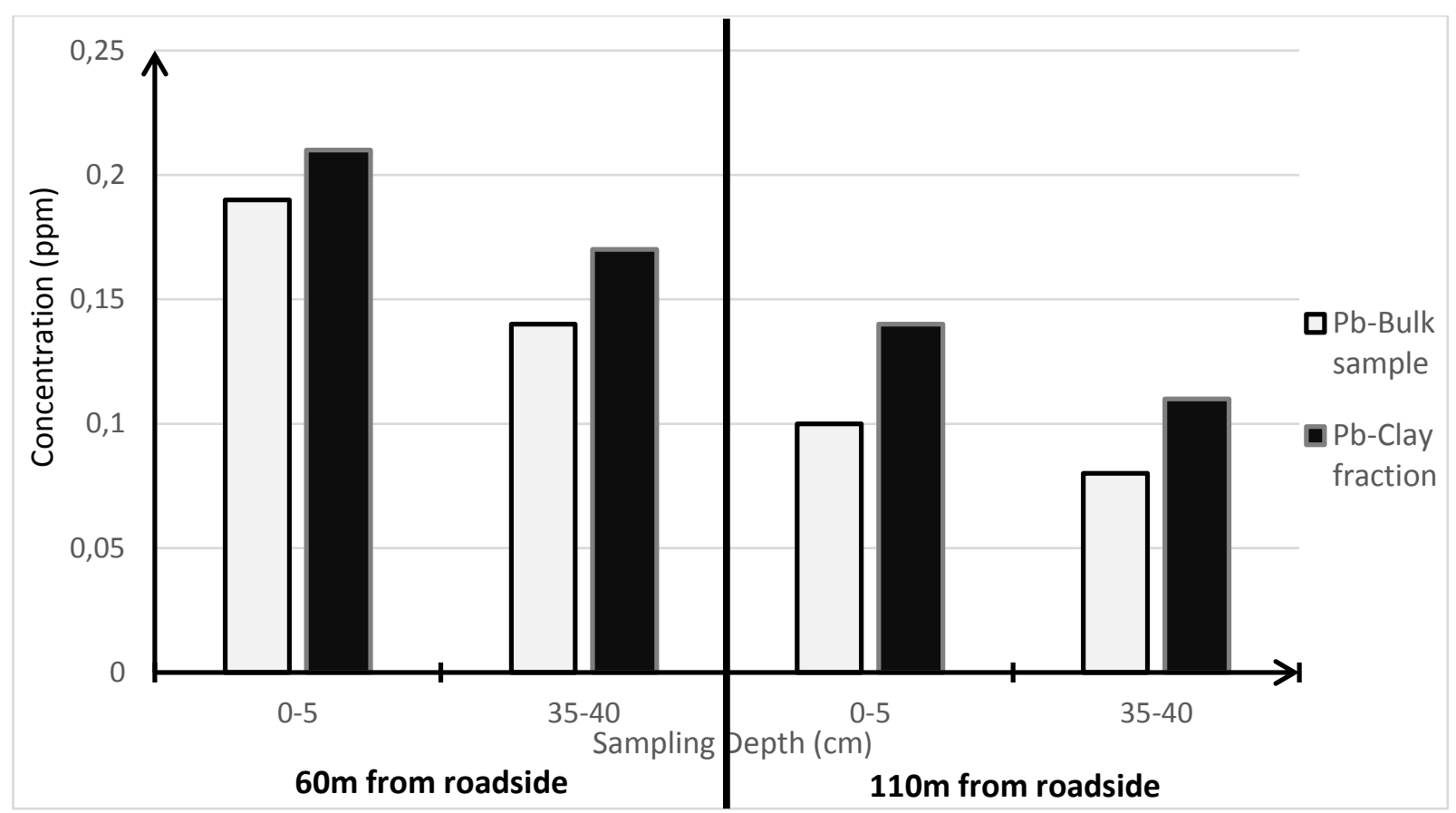

Figure $\mathbf{8 b}$. Vertical distribution of lead in the bulk and clay samples at $60 \mathrm{~m}$ and $110 \mathrm{~m}$ from the roadside

\subsubsection{Copper (Cu)}

The amount of copper in the roadside soils ranged from 8.70 to $18.72 \mathrm{ppm}$ with the mean value of $12.97 \mathrm{ppm}$ in the bulk sample at $5 \mathrm{~m}$ from roadside. At $30 \mathrm{~m}$ from roadside, the concentration ranges from 1.14 to $8.21 \mathrm{ppm}$ with mean value of $5.24 \mathrm{ppm}$ in the bulk sample (Table 6). The clay fraction of the sample on the other hand showed higher amount of copper with the mean values of $25.61 \mathrm{ppm}$ at $5 \mathrm{~m}$ from the roadside and $12.03 \mathrm{ppm}$ at $30 \mathrm{~m}$ from the roadside, this shows that the clay fraction of the sample has a high adsorption capacity for copper. These mean values were lower than the permissible value of $20 \mathrm{ppm}$ from the European standard (Romanian Guideline, 1997) with the exception of the mean values that were obtained in the clay fraction at $5 \mathrm{~m}$ from the roadside. The mean values obtained were greater than the target $(0.3 \mathrm{ppm})$ and intervention (10 ppm) values provided by Nigeria Department of Petroleum Resources (Egaspin, 2002) as shown in Table 7, with exception of the mean values for the bulk samples at $30 \mathrm{~m}$ from roadside.

Figure 9a shows the mean with standard deviation bars of copper concentration for bulk and clay sample for $5 \mathrm{~m}$ and $30 \mathrm{~m}$ from the roadside. Figure $9 \mathrm{~b}$ showed a picture of further vertical migration for $60 \mathrm{~m}$ and $110 \mathrm{~m}$ from the roadside. Both Figures $9 a$ and $b$ showed that as the distance from the road increases, there was a decrease in the metal concentration. Also as the soil sampling depth increases, the copper concentration level decreases down the soil profile. However there was no significant difference $(P \leq 0.05)$ in the copper content at all the sampling depths.

\subsubsection{Chromium (Cr)}

The amount of chromium in the roadside soils ranged from 6.11 to $13.58 \mathrm{ppm}$ with the mean value of $9.43 \mathrm{ppm}$ in the bulk sample at $5 \mathrm{~m}$ from roadside. At $30 \mathrm{~m}$ from roadside, the concentration ranges from 1.13 to $9.51 \mathrm{ppm}$ with mean value of $5.03 \mathrm{ppm}$ in the bulk sample (Table 6). The clay fraction of the sample on the other hand showed higher amount of chromium with the mean values of $42.06 \mathrm{ppm}$ at $5 \mathrm{~m}$ from the roadside and $20.96 \mathrm{ppm}$ at $30 \mathrm{~m}$ from the roadside, this shows that the clay fraction of the sample has a high adsorption capacity for chromium. These mean values were lower than the permissible value of 30ppm from the European standard (Romanian Guideline, 1997) with the exception of the mean values that were obtained in 
the clay fraction at $5 \mathrm{~m}$ from the roadside. The clay fraction mean values obtained were higher than the target $(20 \mathrm{ppm})$ but lower thasn the intervention value $(240 \mathrm{ppm})$ values provided by Nigeria Department of Petroleum Resources (Egaspin, 2002) as shown in Table 7.

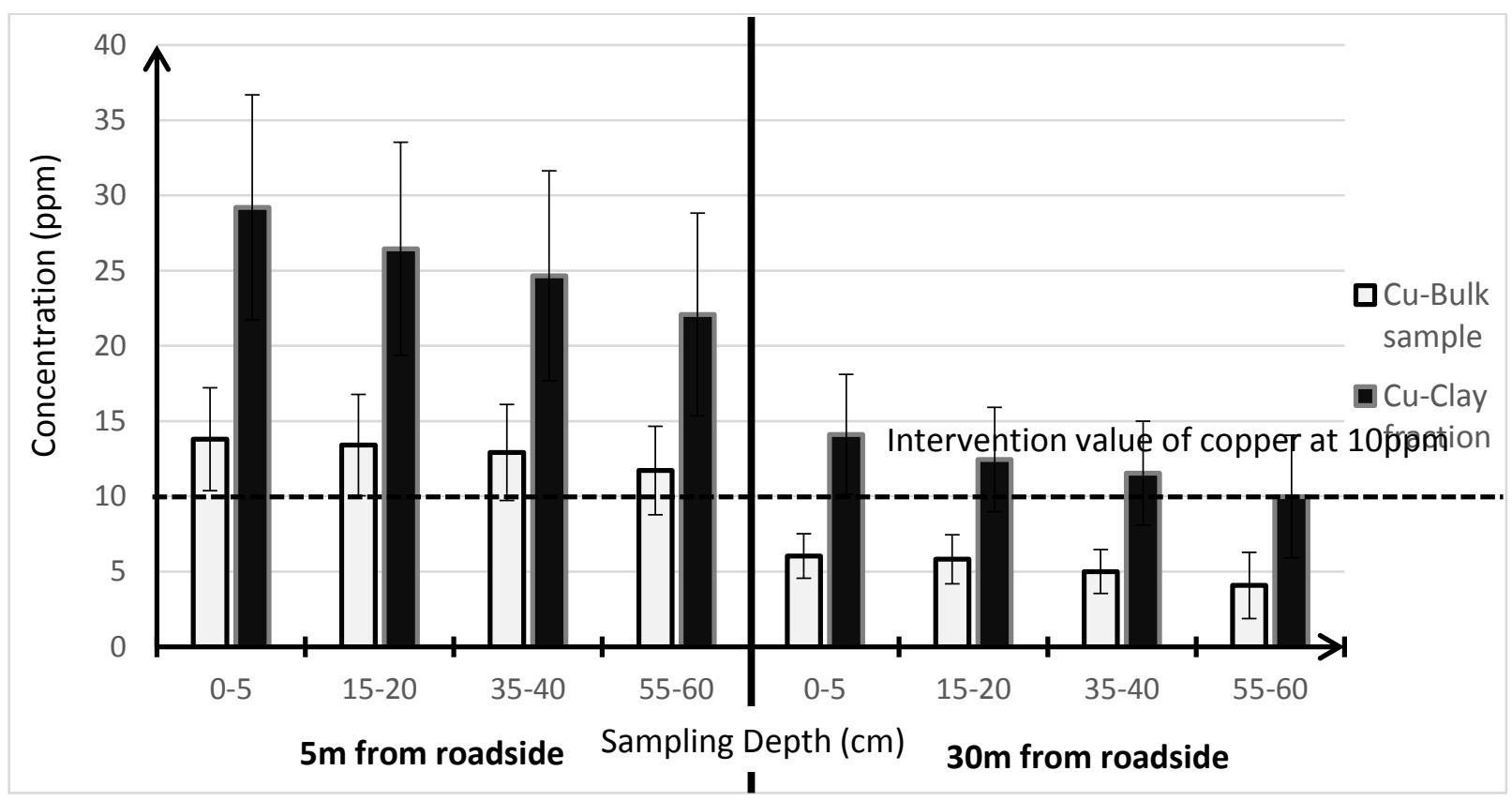

Figure 9a. Mean concentration of copper with standard deviation error bars for bulk sample and clay fraction in roadside soil along Ilesa-Akure road with respect to depth and distance

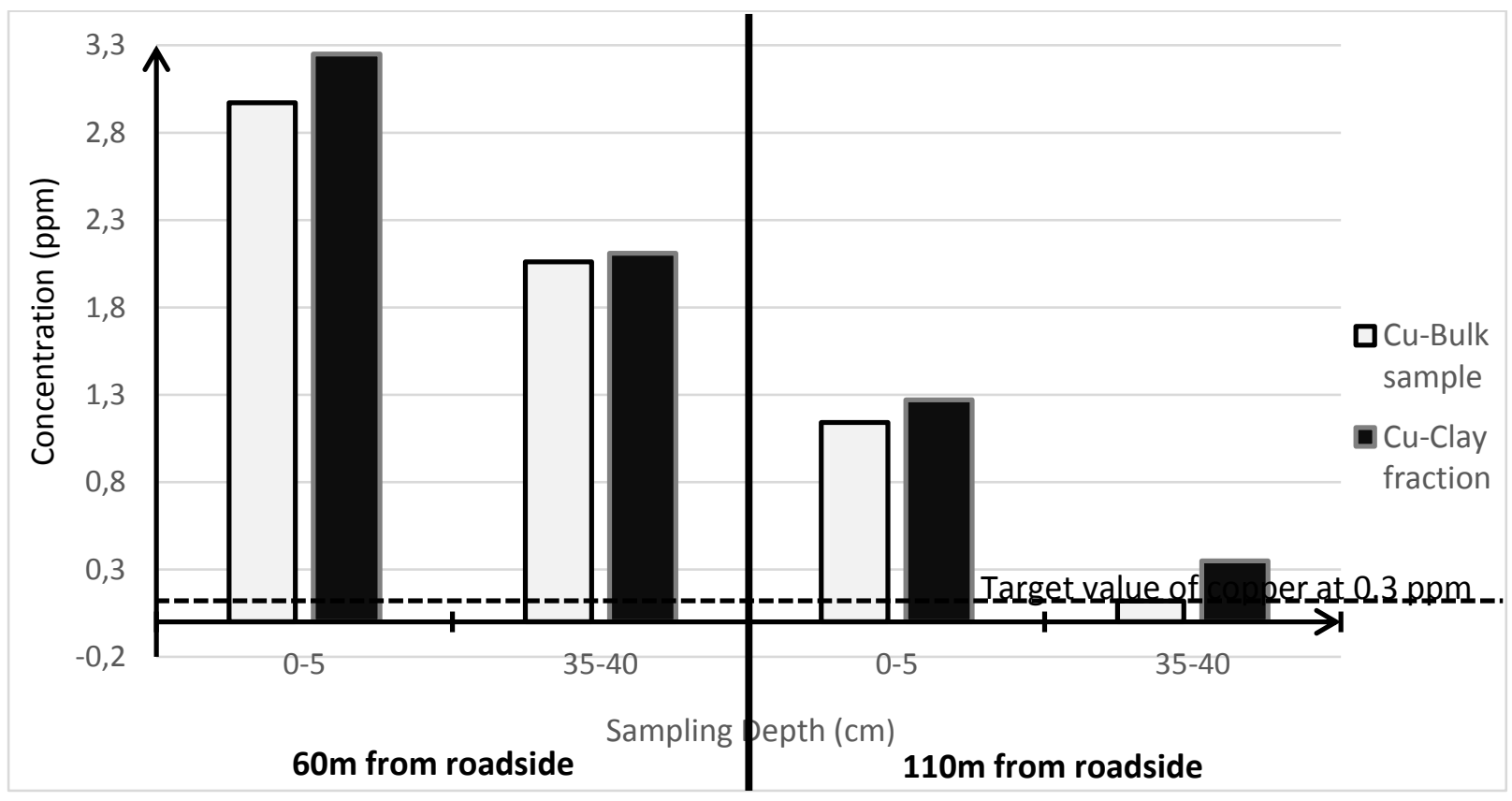

Figure $9 \mathrm{~b}$. Vertical distribution of copper in the bulk and clay samples at $60 \mathrm{~m}$ and $110 \mathrm{~m}$ from the roadside

Figure 10a shows the mean with standard deviation bars of chromium concentration for bulk and clay sample for $5 \mathrm{~m}$ and $30 \mathrm{~m}$ from the roadside. Figure $10 \mathrm{~b}$ showed a picture of further vertical migration for $60 \mathrm{~m}$ and 
$110 \mathrm{~m}$ from the roadside. Both Figures $10 \mathrm{a}$ and $\mathrm{b}$ showed that as the distance from the road increases, there was a decrease in the metal concentration. Also as the soil sampling depth increases, the chromium concentration level increases down the soil profile. The mean concentration of chromium at depth range of $0-5 \mathrm{~cm}$ was lesser (but not significant) than the mean concentration of chromium at depth range of $15-20 \mathrm{~cm}$ and also lesser (but not significant) than the mean concentration of chromium at depth range of $35-40 \mathrm{~cm}$. The mean concentration of chromium at depth range of $0-5 \mathrm{~cm}$ was significantly lesser than the mean concentration of chromium for depth range of $55-60 \mathrm{~cm}$. Hence there was a significant $(P \leq 0.05)$ increase in the chromium content with regard to depth down the soil profile.

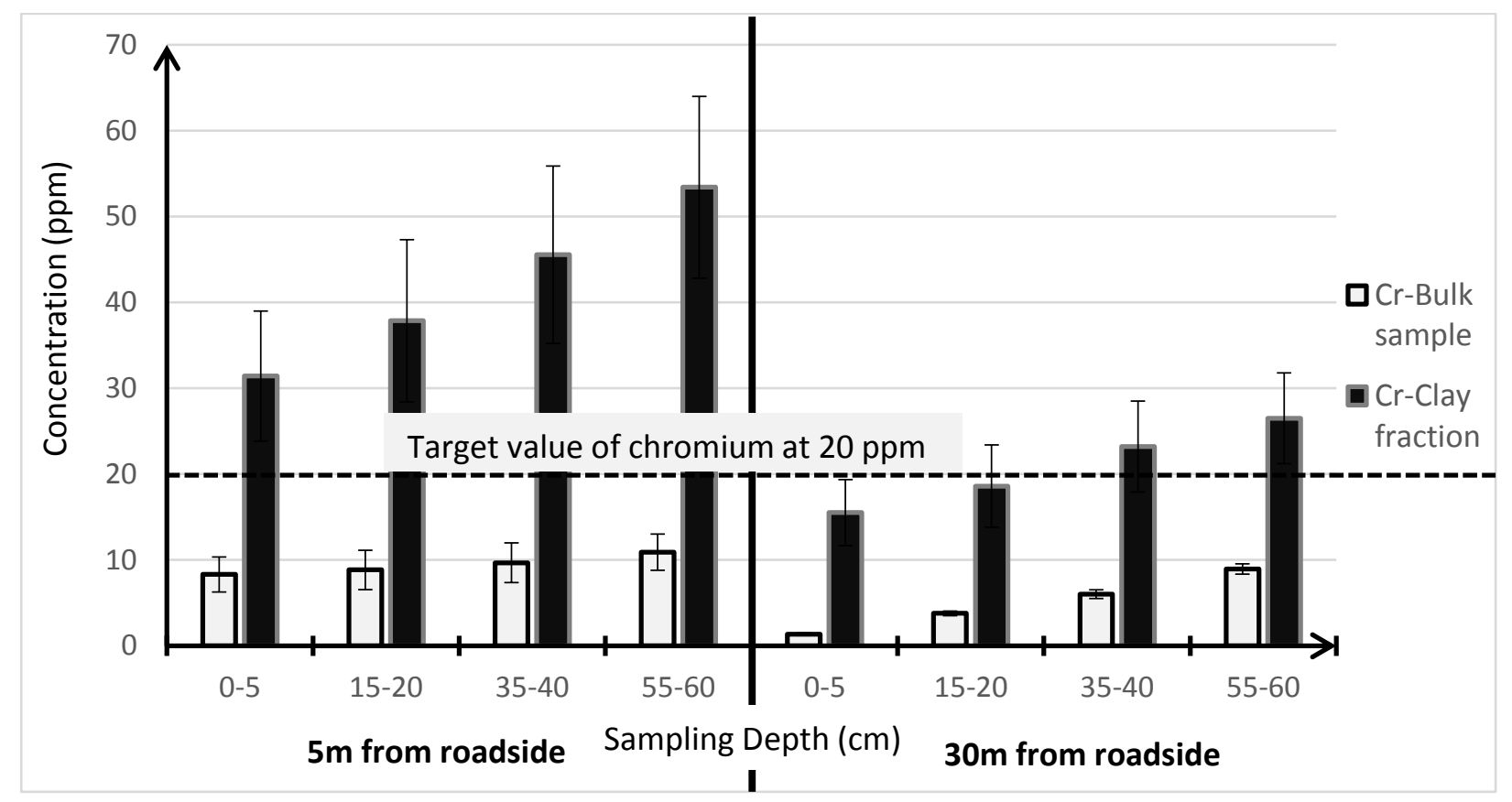

Figure 10a. Mean concentration of chromium with standard deviation error bars for bulk sample and clay fraction in roadside soil along Ilesa-Akure road with respect to depth and distance

\subsubsection{Nickel (Ni)}

The amount of nickel in the roadside soils ranged from 1.36 to $8.61 \mathrm{ppm}$ with the mean value of $4.49 \mathrm{ppm}$ in the bulk sample at $5 \mathrm{~m}$ from roadside. At $30 \mathrm{~m}$ from roadside, the concentration ranges from 0.20 to 4.86 ppm with mean value of $1.49 \mathrm{ppm}$ in the bulk sample (Table 6). The clay fraction of the sample on the other hand showed higher amount of nickel with the mean values of $17.10 \mathrm{ppm}$ at $5 \mathrm{~m}$ from the roadside and 4.92 $\mathrm{ppm}$ at $30 \mathrm{~m}$ from the roadside, this shows that the clay fraction of the sample has a high adsorption capacity for nickel. These mean values were lower than the permissible values, target (140 ppm) and intervention value $(720 \mathrm{ppm})$ provided by Nigeria Department of Petroleum Resources (Egaspin, 2002) as shown in Table 7.

Figure 11a shows the mean with standard deviation bars of nickel concentration for bulk and clay sample for $5 \mathrm{~m}$ and $30 \mathrm{~m}$ from the roadside. Figure $11 \mathrm{~b}$ showed a picture of further vertical migration for $60 \mathrm{~m}$ and $110 \mathrm{~m}$ from the roadside. Both Figures $11 \mathrm{a}$ and $\mathrm{b}$ showed that as the distance from the road increases, there was a decrease in the metal concentration. Also as the soil sampling depth increases, the nickel concentration level increases down the soil profile, this was in agreement with the study carried out by Joseph et al, (2013). 


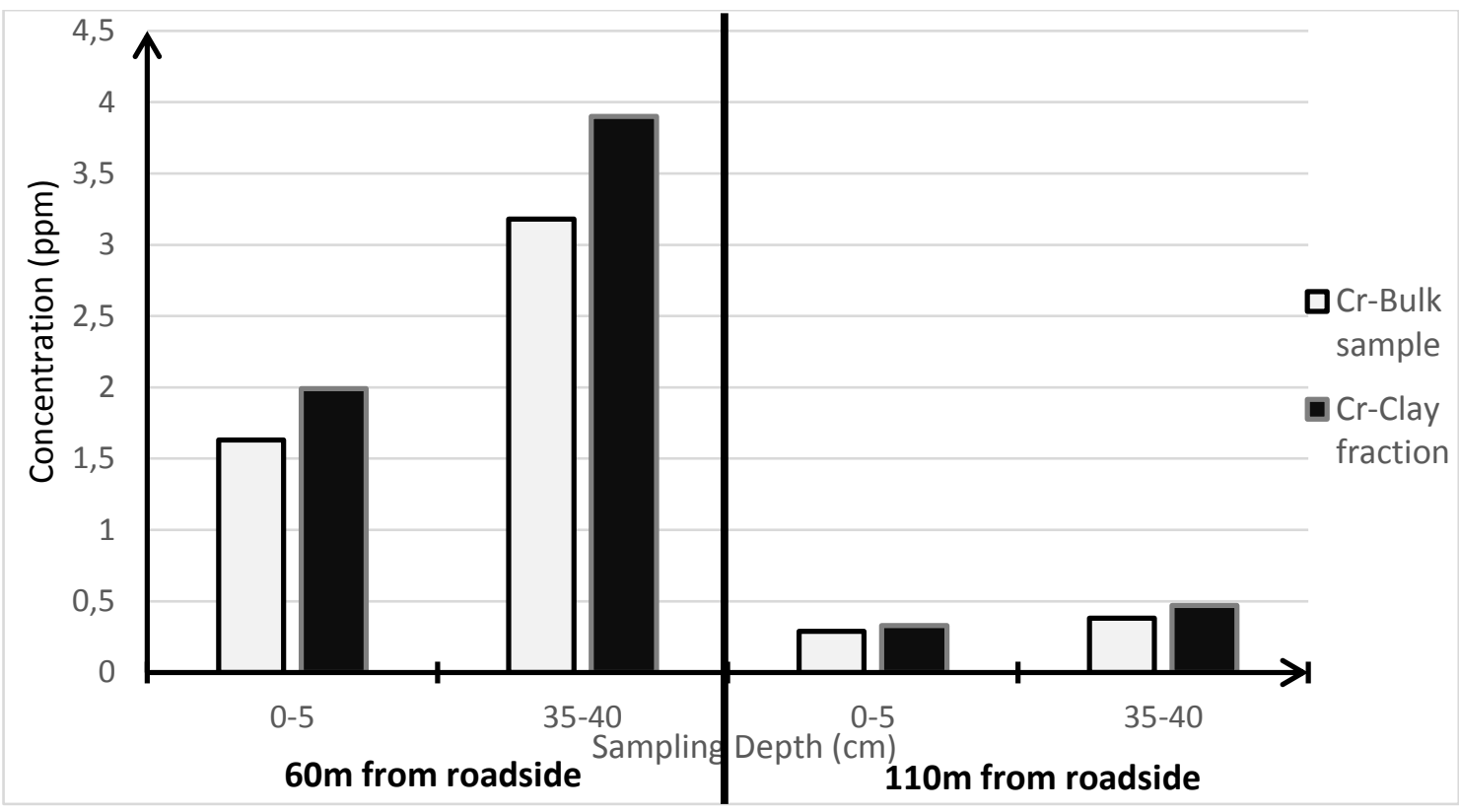

Figure 10b. Vertical distribution of chromium in the bulk and clay samples at $60 \mathrm{~m}$ and $110 \mathrm{~m}$ from the roadside

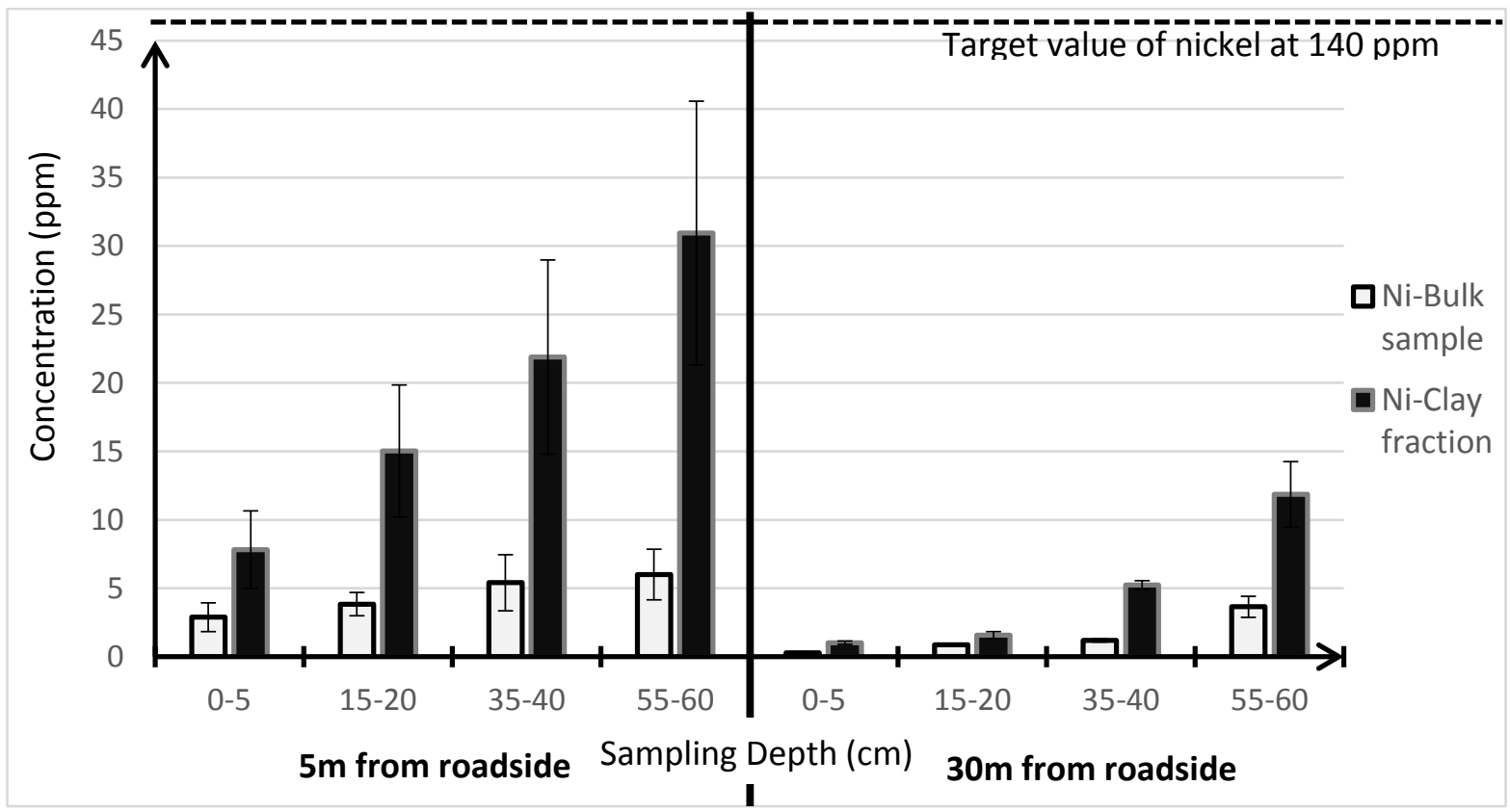

Figure 11a. Mean concentration of nickel with standard deviation error bars for bulk sample and clay fraction in roadside soil along Ilesa-Akure road with respect to depth and distance

The mean concentration of nickel at depth range of $0-5 \mathrm{~cm}$ was lesser (but not significant) than the mean concentration of nickel at depth range of $15-20 \mathrm{~cm}$. The mean concentration of nickel at depth range of 0-5 cm was significantly lesser than the mean concentration of nickel for depth range of $35-40 \mathrm{~cm}$ and also significantly lesser than the mean concentration of nickel at depth range of $55-60 \mathrm{~cm}$. The mean concentration of nickel at depth range of $15-20 \mathrm{~cm}$ was significantly lesser than the mean concentration of nickel for depth range of $35-40 \mathrm{~cm}$ and also significantly lesser than the mean concentration of nickel at depth range of 
$55-60 \mathrm{~cm}$. The mean concentration of nickel at depth range of 35-40 $\mathrm{cm}$ was significantly lesser than the mean concentration of nickel for depth range of $55-60 \mathrm{~cm}$. Hence there was a significant $(P \leq 0.05)$ increase in the nickel content with regard to depth down the soil profile.

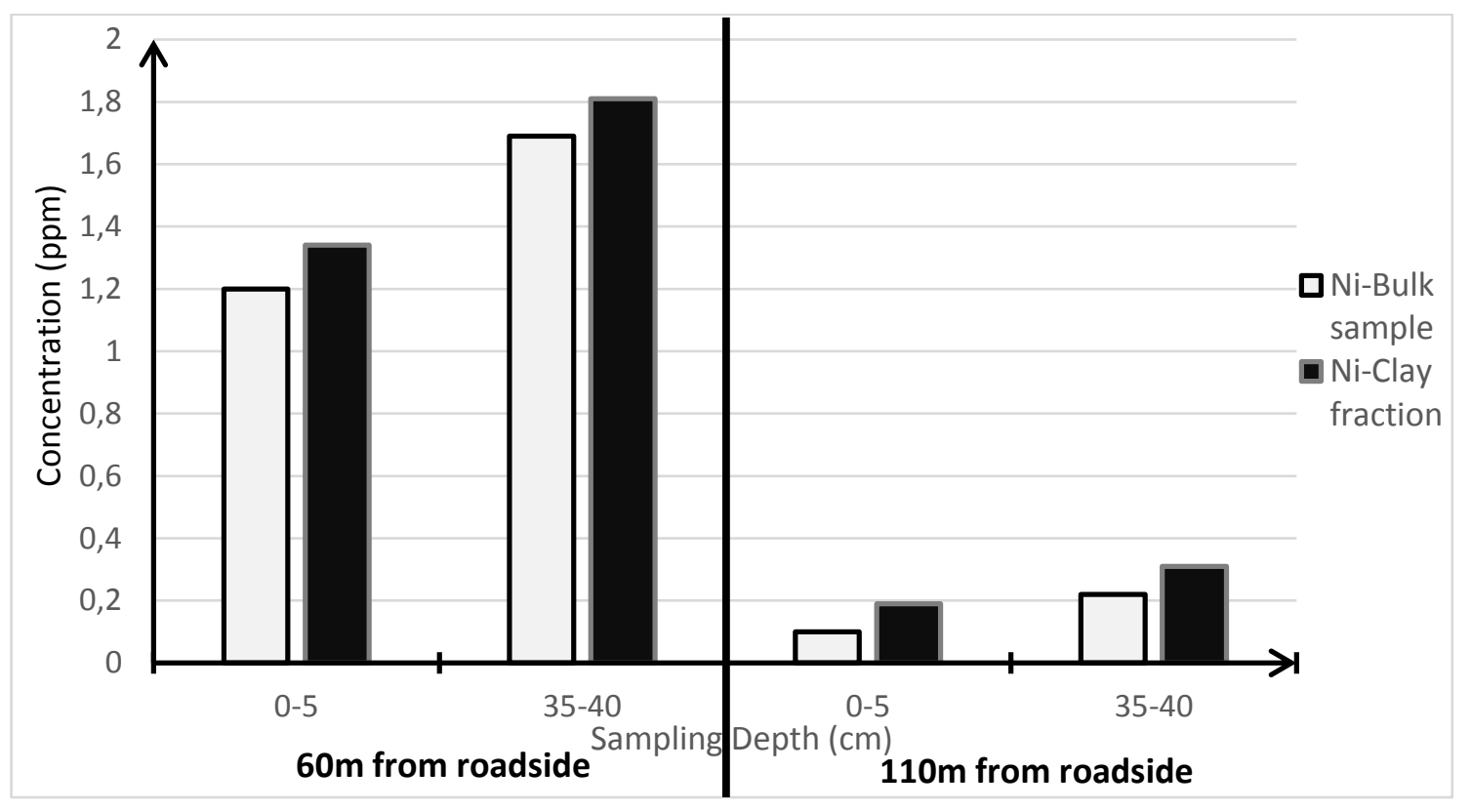

Figure 11b. Vertical distribution of nickel in the bulk and clay samples at $60 \mathrm{~m}$ and $110 \mathrm{~m}$ from the roadside

Table 9 summarizes the significant differences between the Mean concentrations of selected heavy metals with regard to sampling depth. Four of the metals as shown in Table 9 were significantly different with regard to sampling depths.

Table 9. Significant differences between mean concentrations of heavy metals with regards to depth

\begin{tabular}{ccc}
\hline Metal & Significant differences with depth $(\mathbf{c m})$ & Increase or decrease with depth \\
\hline Zinc & $0-5>15-20>35-40>55-60$ & Decrease \\
\hline Lead & $0-5>35-40,55-60$ & Decrease \\
\hline Chromium & $0-5<55-60$ & Increase \\
\hline Nickel & $0-5<35-40,55-60 ; 15-20<35-40,55-60 ; 35-40<55-60$ & Increase \\
\hline
\end{tabular}

\subsection{Contamination Assessment}

Based on heavy metals concentration in studied soil samples, a quantitative analysis of soil contamination around Ilesha-Akure Road (Southwest, Nigeria) was conducted using the $I_{\text {geo }}$ and $P I$ indexes. The results of analysis showed that the $I_{\text {geo }}$ were in the order of $\mathrm{Cu}(2.76)<\mathrm{Pb}(2.87)<\mathrm{Zn}(3.11)<\mathrm{Ni}(3.97)<\mathrm{Cr}(4.25)$. The $I_{\text {geo }}$ values calculated from Equation (1) for the selected heavy metals revealed that copper and lead fell into class 3 (Moderately to strongly contaminated) while zinc and nickel fell into class 4 (Strongly contaminated), chromium fell into class 5 (Strongly to extremely contaminated). The analysis of Pollution Index (PI) showed that the values calculated from Equation (2) just like the $I_{\text {geo }}$ were in the order of $\mathrm{Cu}(10.21)<\mathrm{Pb}(11)<\mathrm{Zn}$ $(12.92)<\mathrm{Ni}(23.63)<\mathrm{Cr}(28.58)$. All the $\mathrm{Pl}$ values indicated that the soil has high contamination of all the selected heavy metals.

\section{Conclusions}

Based on the laboratory test that were conducted in this study, the following conclusions were drawn: 
- The clay fraction of the soil has a good adsorption capacity for heavy metals than the bulk sample with the exception of lead.

- Heavy metals distribution along the soil depth were affected by the soil physicochemical properties with the exception of chromium and nickel, the concentration of the heavy metals decreased with increase in sampling depth.

- The concentration of the selected heavy metals from the sampling site decreased with increasing distance from the road.

- The calculated results of geo-accumulation and pollution indexes of heavy metals revealed that both the order of $I_{\text {geo }}$ and $\mathrm{Pl}$ was as follows: $\mathrm{Cu}<\mathrm{Pb}<\mathrm{Zn}<\mathrm{Ni}<\mathrm{Cr}$.

- The concentration of heavy metals along the llesa-Akure is gradually moving towards target and intervention values, hence they should be checked. This would make environmental baseline provision for the reality of suburbanization in Nigerian cities.

\section{References}

Achi M.M., Uzairu A., Gimba C.E. and Okunola O.J. (2011), Chemical Fractionation of Heavy Metals in Soils around the vicinity of Automobile Workshops in Kaduna Metropolis, Nigeria, Journal of Environmental Chemistry and Ecotoxicology, 3(7), 184-194.

Adelekan B.A. and Alawode A.O. (2011), Contributions of municipal refuse dumps to heavy metals concentrations in soil profile and groundwater in Ibadan Nigeria, Journal of Applied Biosciences, 40, 2727 - 2737.

Al-Khashman O.A. (2004), Heavy metal distribution in dust, street dust and soils from the work place in Karak Industrial Estatem, Jordan, Atmospheric Environment, 38, 6803-6812.

Azeez J.O., Hassan O.A. and Egunjobi P.O. (2011), Soil Contamination at Dumpsites: Implication of Soil Heavy Metals Distribution in Municipal Solid Waste Disposal System: A Case Study of Abeokuta, Southwestern Nigeria, Soil and Sediment Contamination: An International Journal, 20(4), 370-386.

Banerjee A.D.K. (2003), Heavy metal levels and solid phase speciation in street dusts of Delhi, India, Environmental Pollution, 123, 95-105.

Chen X., Xia X., Zhao Y. and Zhang P. (2010), Heavy metal concentrations in roadside soils and correlation with urban traffic in Beijing, China, Journal of Hazardous Materials, 181, 640-646.

Cheung K.C., Poon B.H.T., Lan C.Y. and Wong M.H. (2003), Assessment of metal and nutrient concentrations in river water and sediment collected from the cities in the Pearl River Delta, South China, Chemosphere, 52, 1431-1440.

Christoforidis A. and Stamatis N. (2009), Heavy metal contamination in street dust and roadside soil along the major national road in Kavala's region, Greece, Geoderma, 151, 257-263

De la Rosa G. Peralta-Videa J.R. and Gardea-Torresdey J.L. (2003), Utilization of ICP/OES for the determination of Trace Metals Binding to Different Humic Fractions, Journal of Hazardous Materials, 97, 207-218.

Dolan L.M.J., Van Bohemen H., Whelan P., Akbar K.F., O'Malley V., O' leary G. and Keizer P.J. (2006), Towards the sustainable development of modern road ecosystem. In: DAVENPORT J., DAVENPORT J.L. (eds.).The Ecology of Transportation: Managing Mobility for the Environment. Springer Netherlands, 275-331.

Dube A., Zbytniewski R., Kowalkowski T., Cukrowska E. and Buszewski B. (2001), Adsorption and Migration of Heavy Metals in Soil, Polish Journal of Environmental Studies 10(1), 1-10.

Duong T.T. and Lee B.K. (2011), Determining contamination level of heavy metals in road dust from busy traffic areas with different characteristics, Journal of Environmental Management, 92, 554-562.

EGASPIN (2002), Environmental Guidelines and Standards for the Petroleum Industry in Nigeria (EGASPIN), Department of Petroleum Resources, Lagos, Nigeria. 
Gonzalez - Fernandez O., Hidalgo M., Margui E., Carvalho M.L. and Queralt I. (2008), Heavy Metals Content of Automotive Shredder Residues (ASR): Evaluation of environmental risk, Environmental Pollution, 153, 476-482.

Iwegbue C.M., Nwajei G.E., Ogala J.E. and Overah C.L. (2010), Determination of trace metal concentrations in soil profiles of municipal waste dumps in Nigeria, Environmental Geochemistry and Health, 32(5), 415-430.

Jones L.H.P., Jarvis S.C., Green D.J. and Hayes M.H.B. (1981), The Fate of Heavy Metals in the Chemistry of Soil Processes, John Wiley \& Sons New York, NY, USA, 593.

Kummer U., Pacyna J., Pacyna E. and Friedrich R. (2009), Assessment of heavy metal releases from the use phase of road transport in Europe, Atmospheric Environment, 43, 640-647.

Lee P.K., Yu Y.H. ,Yun S.T. and Mayer B. (2005), Metal contamination and solid phase partitioning of metals in urban roadside sediments, Chemosphere, 60, 672-689.

Lu X., Wang L., Lei K., Huang J. and Zhai Y. (2009), Contamination assessment of copper, lead, zinc, manganese and nickel in street dust of Baoji, NW China, Journal of Hazardous Materials, 161, 1058-1062.

Matini L., Moutou J.M., Ongoka P.R. and Tathy J.P. (2011), Clay Mineralogy and Vertical Distribution of Lead, Zinc and Copper in a Soil Profile in the Vicinity of an Abandoned Treatment Plant, Research Journal of Environmental and Earth Sciences, 3(2), 114-123.

Modrzewska B. and Wyszkowski M. (2014), Trace metals content in soils along the state road 51 (Northeastern Poland), Environmental Monitoring and Assessment, 186, 2589-2597.

Nixon H. and Saphores J.D. (2007), Impacts of motor vehicle operation on water quality in the US - cleanup costs and policies, Transp. Res. Part D: Transp. Environ., 12, 564-576.

Omar N.Y.M.J., Bin-Abas M.R., Rahman N.A., Tahir N.M., Rushdi A.I. and Simoneit B.R.T. (2007), Levels and distributions of organic source tracers in air and roadside dust particles of Kuala Lumpur, Malaysia, Environmental Geology, 52, 1485-1500.

Radziemska M. and Fronczyk J. (2015), Level and Contamination Assessment of Soil along an Expressway in an Ecologically Valuable Area in Central Poland, International Journal of Environmental Research and Public Health, 12, 13372-13387.

Rijkenberg M.J. and Depree C.V. (2010), Heavy metal stabilization in contaminated road-derived sediments, Science of the Total Environment, 408, 1212-1220.

Romanian Soil Guideline (1997), Romaniei No. 303 bis/ 6 XII 1997/ OM 756.

Smagunova A.N., Ondar U.V., Molchanova E.I., Vashukevich H.V., Kozlov V.A. and Aprelkov N.G. (2004), X-ray Florescence Determination of Heavy Metals in Humic Acids, Journal of Analytical Chemistry, 59, 1066-1072.

Taseli B.K., Gokcay C.F. and Gurol A. (2008), Influence of nickel (II) and chromium (VI) on the laboratory scale rotating biological contactor, Journal of Industrial Microbiology and Biotechnology, 35(9), 1033-1039.

Varol M. (2011), Assessment of heavy metal contamination in sediments of the Tigris River (Turkey) using pollution indices and multivariate statistical techniques, Journal of Hazardous Materials, 195, 355-364.

Wang A.S., Angle J.S., Chaney R.L., Delorme T.A. and Reeves R.D. (2006), Soil pH effects on uptake of Cd and Zn by Thlaspi caerulescens, Plant Soil, 281(1-2), 325-337.

Warren R.S. and Birch P. (1987), Heavy metal levels in atmospheric particulates, roadside dust and soil along a major urban highway, Science of Total Environment, 59, 233-256.

Wei B., Jiang F., Li X. and Mu S. (2009), Spatial distribution and contamination assessment of heavy metals in urban road dusts from Urumqi, NW China, Microchemical Journal, 93, 147-152.

Yi L., Hong Y., Wang D. and Zhu Y (2007), Determination of free heavy metal ion concentrations in soils around a cadmium rich zinc deposit, Geochemical Journal, 41(4), 235-240.

Yu H., Ni S.J., He Z.W., Zhang C.J., Nan X., Kong B. and Weng Z.Y. (2014), Analysis of the spatial relationship between heavy metals in soil and human activities based on landscape geochemical interpretation, Journal of Geochemical Exploration, 146, 136-148. 